NUREG-1565

\title{
Dry Oxidation and Fracture of LWR Spent Fuels
}

Manuscript Completed: September 1996

Date Published: November 1996

T. M. Ahn

Division of Waste Management

Office of Nuclear Material Safety and Safeguards

U.S. Nuclear Regulatory Commission

Washington, DC 20555-0001

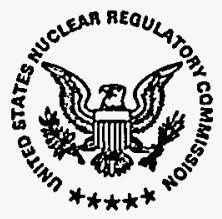

DISTRIBUTION OF THIS DOCURENT IS URLMAITED

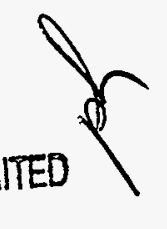




\section{DISCLAIMER}

This report was prepared as an account of work sponsored by an agency of the United States Government. Neither the United States Government nor any agency thereof, nor any of their employees, makes any warranty, express or implied, or assumes any legal liability or responsibility for the accuracy, completeness, or usefülness of any information, apparatus, product, or process disclosed, or represents that its use would not infringe privately owned rights. Reference herein to any specific commercial product, process, or service by trade name, trademark, manufacturer, or otherwise does not necessarily constitute or imply its endorsement, recommendation, or favoring by the United States Government or any agency thereof. The views and opinions of authors expressed herein do not necessarily state or reflect those of the United States Government or any agency thereof. 


\begin{abstract}
This report evaluates the characteristics of oxidation and fracture of light-water reactor (LWR) spent fuel in dry air. It also discusses their effects on radionuclide releases in the anticipated high-level waste repository environment. A sphere model may describe diffusionlimited formation of lower oxides, such as $\mathrm{U}_{4} \mathrm{O}_{9}$, in the oxidation of the spent fuel (SF) matrix. Detrimental higher oxides, such as $\mathrm{U}_{3} \mathrm{O}_{8}$, may not form at temperatures below a threshold temperature. The nucleation process suggests that a threshold temperature exists. The calculated results regarding fracture properties of the SF matrix agree with experimental observations. Oxidation and fracture of Zircaloy may not be significant under anticipated conditions. Under saturated or unsaturated aqueous conditions, oxidation of the SF matrix is believed to increase the releases of Pu-(239+240), Am- $(241+243), \mathrm{C}-14, \mathrm{Tc}-99, \mathrm{I}-129$, and Cs-135. Under dry conditions, I-129 releases are likely to be small, unlike C-14, in lower oxides; Cl-36, Tc-99, I-129, and Cs-135 may be released fast in higher oxides.
\end{abstract}




\section{DISCLAIMER}

Portions of this document may be illegible in electronic image products. Images are produced from the best available original document. 


\section{CONTENTS}

Page

Abstract $\ldots \ldots \ldots \ldots \ldots \ldots \ldots \ldots \ldots \ldots \ldots \ldots \ldots \ldots \ldots \ldots$ iii

Acknowledgments $\ldots \ldots \ldots \ldots \ldots \ldots \ldots \ldots \ldots \ldots \ldots$ vii

Abbreviations $\ldots \ldots \ldots \ldots \ldots \ldots \ldots \ldots \ldots \ldots \ldots \ldots \ldots \ldots \ldots \ldots \ldots$ viii

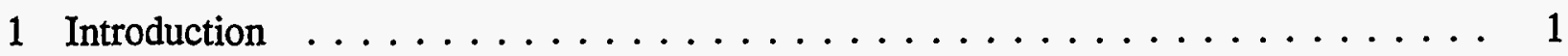

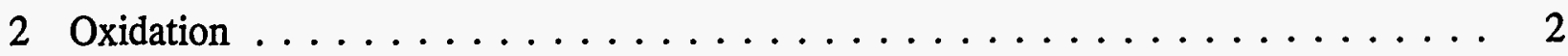

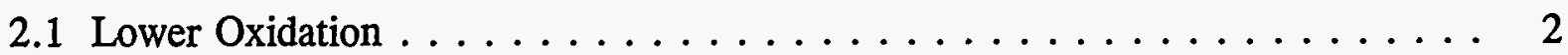

2.2 Higher Oxidation $\ldots \ldots \ldots \ldots \ldots \ldots \ldots \ldots \ldots \ldots \ldots \ldots \ldots \ldots$

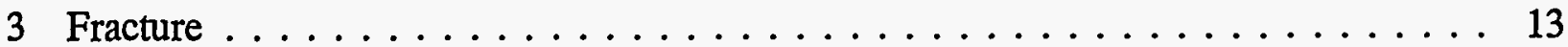

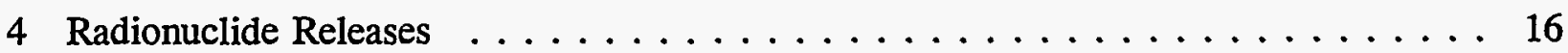

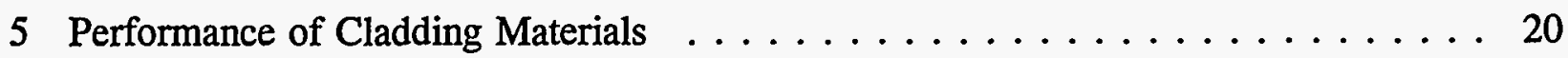

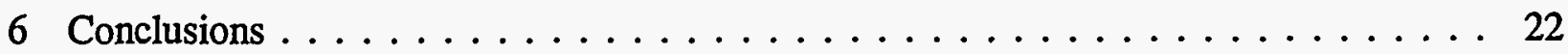

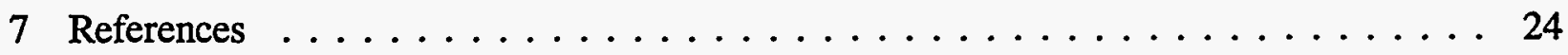

Figures

1 Weight Changes of Oxidized Bare Fragments of Turkey Point Fuel at Temperatures From 250 to $360 \mathrm{C} \ldots \ldots \ldots \ldots \ldots \ldots$

2 Time Dependence of $\mathrm{U}_{4} \mathrm{O}_{9}$ Growth in Air-Oxidized LWR SF at

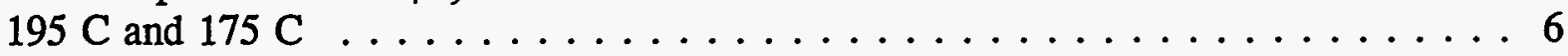

3 Generalized Curve Representing the O/M State of SF as a Function of Oxidation Time $\ldots \ldots \ldots \ldots \ldots \ldots \ldots$ 
CONTENTS (continued)

Tables

Page

1 Calculated Times To Complete the Oxidation of $\mathrm{UO}_{2}$ to $\mathrm{UO}_{2.4} \ldots \ldots \ldots$

2 Calculated Relative Values of Time Delay $\ldots \ldots \ldots \ldots \ldots \ldots$

3 Calculated Relative Values of Hypothetical Activities to " $\mathrm{C}_{\mathrm{B}}$ ".

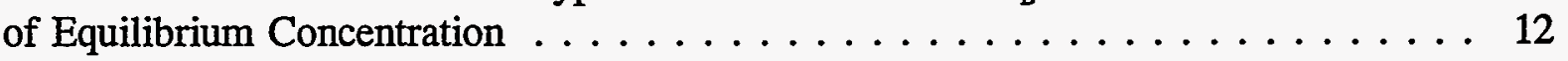

4 Differential Stress Caused by $\mathrm{UO}_{2}$ Oxidation $\ldots \ldots \ldots \ldots \ldots \ldots$

5 Calculated Surface Areas Associated With Fractures in 100 -Percent Oxidized SF . . . . . . . . . . . . . . . 16

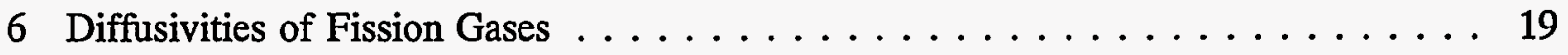

7 Calculated Cladding Thickness Oxidized and Transition Time From Protective Pretransition Oxide to Non-Protective

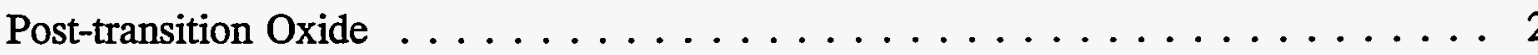




\section{ACKNOWLEDGMENTS}

This work was conducted for the implementation of the Nuclear Regulatory Commission's Key Technical Issue (KTI) plan for the Container Life and Source Term. The author is thankful for NRC management's support for this work. The manuscript was reviewed by staff of the NRC and staff of the Center for Nuclear Waste Regulatory Analyses. The author is grateful for their suggestions and comments. The author also thanks Dr. P. Taylor of Atomic Energy of Canada Limited, Drs. R. Einziger and W. Gray of Pacific Northwest Laboratory, and Dr. Hj. Matzke of EC Institute for Transuranium Elements, for reviewing this manuscript and commenting on it. 


\section{ABBREVIATIONS}

$\begin{array}{ll}\text { AECL } & \text { Atomic Energy of Canada, Ltd. } \\ \text { ASM } & \text { American Society for Metals } \\ \text { BWR } & \text { boiling-water reactor } \\ \text { CANDU } & \text { Canadian Deuterium-Natural Uranium Reactor } \\ \text { DOE } & \text { Department of Energy } \\ \text { EBS } & \text { engineered barrier system } \\ \text { HLW } & \text { high-level waste } \\ \text { KTI } & \text { key technical issue } \\ \text { LWR } & \text { light-water reactor } \\ \text { MGDS } & \text { mined geological disposal system } \\ \text { PNL } & \text { Pacific Northwest Laboratory } \\ \text { PWR } & \text { pressurized-water reactor } \\ \text { SF } & \text { spent fuel } \\ \text { TSPA } & \text { total system performance assessment } \\ \text { YM } & \text { Yucca Mountain }\end{array}$




\section{INTRODUCTION}

The implementation of the Nuclear Regulatory Commission's Key Technical Issue (KTI) plan for the Container Life and Source Term evaluates and conducts sensitivity analyses on the performance of the U. S. Department of Energy's (DOE's) engineered barrier system (EBS) for the mined geological disposal system (MGDS) planned at the Yucca Mountain (YM) repository site. A technical assessment requirement of this KTI is to evaluate the interaction of spent fuel (SF) with gaseous oxygen, in potential dry environments. The SF is a primary EBS component.

This report evaluates the processes involved in the dry oxidation and fracture of SF that are responsible for fast radionuclide releases from SF. This assessment will support the development of methodology for evaluating licensing applications for high-level waste (HLW) disposal. In the total system performance assessments (TSPAs) of emplaced HLW, verified values (or formulas) of radionuclide releases will be used as input sources, and assumptions and potential physical processes will be used in determining various cases (scenarios).

SF oxidation has been studied as part of HLW TSPA. Oxidation is a precursory step to fast SF dissolution or increases solubility limits of various radionuclides under aqueous conditions. It also leads to radionuclide release from SF under dry conditions. The currently proposed YM U.S. repository may be dry, unsaturated (i.e., drip conditions of groundwater), or saturated (i.e., immersion conditions of groundwater) as time elapses. In these environments, dry-air oxidation may play an important role in radionuclide releases. $\mathrm{UO}_{2}$ matrices will fracture (or crack) upon oxidation by volume change. Lower oxides such as $\mathrm{UO}_{2.4}$ will contract, whereas higher oxides such as $\mathrm{U}_{3} \mathrm{O}_{8}$ or $\mathrm{UO}_{3}$ hydrates will expand. Lower and higher oxides are defined here as oxides of $(\mathrm{O} / \mathrm{U})$ ratio smaller and larger than 2.4, respectively. Fracture can increase the exposed area of an SF surface to groundwater or to air. In turn, this increase of the exposed surface area is expected to affect radionuclide release behavior.

Gaseous radionuclides and high-solubility radionuclides will be released in proportion to this increased surface area as a first-order approximation. C-14, Cl-36, and I-129 are examples of gaseous radionuclides. Additionally, diffusional release behavior of gaseous radionuclides within the SF matrix changes as oxidation proceeds. C-14, I-129, Tc-99, and Cs-135 are examples of high-solubility radionuclides. High-solubility radionuclides are released at rates of the matrix dissolution times the total area of exposed surface. The low-solubility radionuclides are mainly actinides such as Pu- $(239+240)$ or Am- $(241+243)$. These actinides will be released by the flow of groundwater with dissolved ions (of solubility limits) or with colloids. The increase of surface area may facilitate colloid formation or supersaturate the groundwater with radionuclides above solubility limits.

In this report, SF oxidation in dry-air environments will be considered first. Existing theories of diffusion-limited oxidation will be evaluated for lower oxidation. Then, existing data will be interpreted in terms of reaction-limited oxidation for higher oxidation. Second, the process 
of fracture associated with oxidation will be investigated. On the basis of these evaluations, radionuclide releases associated with oxidation and fracture will be discussed. Cladding failure by oxidation will also be evaluated. Throughout this report, data at temperatures other than anticipated repository temperatures will also be discussed. Discussions of these other temperatures are useful when (a) the data can be extrapolated to the anticipated repository conditions, (b) oxidation mechanisms under the anticipated repository conditions can be inferred from such data, (c) such data are potentially useful under unanticipated repository conditions, and (d) such data are potentially useful to optimize waste package design.

\section{OXIDATION}

\subsection{Lower Oxidation}

Researchers have studied the solid-state oxidation of $\mathrm{UO}_{2}$ (to $\mathrm{U}_{3} \mathrm{O}_{7}$ or $\mathrm{U}_{3} \mathrm{O}_{8}$ ) in air. Einziger at Pacific Northwest Laboratory (PNL) (Einziger, 1992; Einziger et al., 1992; Einziger and Buchanan, 1988) and Taylor and his coworkers (1991) at Atomic Energy of Canada Limited (AECL) have recently summarized such oxidation studies. Irradiated LWR SF has shown quite different behavior in oxidation from $\mathrm{UO}_{2}$ or SF surrogates such as SIMFUEL (Campbell et al., 1989a,b). Temperature, moisture, and irradiation have been considered the most important factors in controlling oxidation behavior of SF in dry-air environments.

In the high-temperature regime of above $250 \mathrm{C}$, higher oxide formation has been an important concern. Higher oxidation leads to powdering of the SF matrix. At repository temperatures below $200 \mathrm{C}$, an intermediate phase $\mathrm{UO}_{2.4}\left(\mathrm{U}_{4} \mathrm{O}_{9}\right.$ structure $)$ has been found to form, for up to approximately four years. Compared with higher oxides, this intermediate phase is considered less detrimental, because of smaller volume contractions upon oxidation. Unlike $\mathrm{SF}, \mathrm{UO}_{2}$ oxidizes to form $\mathrm{U}_{3} \mathrm{O}_{7}$ as the intermediate phase (Taylor et al., 1991). With moisture at 200 to $225 \mathrm{C}$, water oxidizes $\mathrm{UO}_{2}$ only with the assistance of air or oxidants (Taylor et al., 1991). In water or with moisture levels in excess of 50-percent saturated steam, precipitated $\mathrm{UO}_{3}$ hydrates, dehydrated schoepite, or precipitated $\mathrm{U}_{3} \mathrm{O}_{8}$ have been observed (Taylor et al., 1991). Other mineral phases such as uranosilicates also have been observed in saturated and unsaturated aqueous environments (Wronkiewicz et al., 1992). Therefore, aqueous oxidation is generally faster than dry oxidation. The presence of radiogenic oxidizers in saturated environments especially may help form higher oxides (Grambow, 1989). The exceptional case includes the reverse trend; SF in air oxidizes faster than uraninite (i.e., an SF analogue) submerged in oxygenated water (Posey-Dowty et al., 1987). The acceleration can be by a factor of more than 1,000 . However, there is controversial evidence, as well. In practice, the PNL group has concluded that moisture (dew points $\leq 80 \mathrm{C}$ ) has little or no effect on the total rate and extent of oxidation of pressurizedwater reactor (PWR) SF at 110 to 225 C (Einziger, 1992; Einziger and Buchanan, 1988). However, it should be noted that aqueous conditions are likely to exist at YM. Aqueous conditions will facilitate oxide formation at lower temperatures (Wronkiewicz et al., 1992; Taylor et al., 1992a). 
The mechanisms for low-temperature oxidation of $\mathrm{UO}_{2}$ or SF have not been well understood. Currently, models are available only for simple cases such as the diffusion limit. Recently, Stout and his coworkers (1993a,b) attempted to quantify kinematics and energetics, associated with SF oxidation, for complicated cases. They formulated this quantification for continuous and discontinuous media, incorporating equilibrium and nonequilibrium aspects of phase transformation. Although their work is expected to be a guideline for future experimental work, its applicability to the current practice of TSPA is limited. The available experimental data are not detailed enough to be analyzed in terms of Stout and his coworkers' formulation. Nevertheless, it is noted that this work addresses various potential candidate mechanisms other than the diffusion-limited mechanism. Some experimental observations have suggested that these alternate mechanisms may govern SF oxidation. For instance, Tempest and his coworkers (1988) recognized that interface reaction controls growth rate of $\mathrm{U}_{3} \mathrm{O}_{7}$ in $\mathrm{UO}_{2}$ at 230 to $270 \mathrm{C}$. Even in diffusion limits, traditional simple boundary conditions may need to be modified. Examples are microscopic inhomogeneities. The microscopic inhomogeneities are composite structures of $\left(\mathrm{UO}_{2}+\mathrm{U}_{3} \mathrm{O}_{7}\right),\left(\mathrm{U}_{4} \mathrm{O}_{9}+\right.$ amorphous $\mathrm{U}_{3} \mathrm{O}_{8}$ ), or (crystalline $\mathrm{U}_{4} \mathrm{O}_{9}+$ amorphous $\mathrm{U}_{4} \mathrm{O}_{9}$ ). Currently available models for oxidation kinetics of $\mathrm{SF}$ and $\mathrm{UO}_{2}$ are mostly based on the diffusion limit. Such models are typically for single mobile species, such as oxygen, in a homogeneous system composed of grain matrices and grain boundaries. First, these traditional formulations will be summarized and evaluated.

Most oxidation experiments have been conducted with moderate burnup fuels (25 to $48 \mathrm{GWd} / \mathrm{MTU}$ ). This SF normally has fission gases trapped at grain boundaries. The trapped gases provide open space at grain boundaries and subsequently facilitate oxygen diffusion for grain-boundary oxidation. Whereas oxidation kinetics of unirradiated fuels show the combined effects of grain-boundary oxidation and matrix oxidation (Campbell et al., 1989a,b), oxidation kinetics of irradiated fuels (especially of small grain sizes) usually show uncoupling of grain-boundary oxidation and matrix oxidation (Einziger et al., 1992, 1991; Campbell et al., 1989b; Woodley et al., 1989; Einziger and Buchanan, 1988). Of course, grain-boundary oxidation precedes matrix oxidation. This experimental observation is further supported by the facts that (a) many data on fission-gas releases during reactor operation were dependent on matrix diffusivity only and (b) grain boundaries are open to a greater extent through sintering, burnup, or oxidation. Nevertheless, researchers have not completely ruled out that low burnup fuels (in the range of $10 \mathrm{GWd} / \mathrm{MTU}$ ) may show coupling effects.

Olander (1986) has summarized the relevant mathematical formulations to describe diffusion problems in nuclear fuels and Codell (1993) has presented a model of SF oxidation. All these formulas focus on how to formulate coupled diffusion (i.e., simultaneous diffusion along grain boundaries and in matrices) and to simplify the formulation. Up to now, the formula for coupled diffusion has not been needed in SF oxidation. The uncoupling effects are expected to be more pronounced as temperature decreases, because the discrepancy between the diffusivity of grain boundary and of matrix becomes more pronounced. Both grainboundary oxidation and matrix oxidation can be described by the sphere model, assuming that fuel particles or fuel grains are spherical. Recently, Stout and his coworkers (1990) considered the effect of grain shape and of grain-size distribution on matrix oxidation. The 
results provide statistically averaged kinetics for total weight gain or for growth of oxidized width in each grain. These kinetics are similar to those derived for a single spherical grain.

Representative experimental data are analyzed to support the preceding hypothesis of uncoupled diffusion in a single sphere. The PNL group has measured oxidation kinetics of LWR SF at temperatures around 200 C (Einziger, 1992; Einziger et al., 1991; Woodley et al., 1989; Einziger and Buchanan, 1988). The data consist of (a) kinetics of matrix oxidation and (b) the time to complete grain-boundary oxidation. Figure 1 shows representative kinetics of SF oxidation. Weight changes of air-oxidized bare fragments of Turkey Point fuel are shown at temperatures from 250 to $360 \mathrm{C}$ (Einziger et al., 1992). Figure 2 shows time dependence of $\mathrm{U}_{4} \mathrm{O}_{9}\left(\mathrm{UO}_{2.4}\right.$ stoichiometry) growth in LWR SF at 195 and $175 \mathrm{C}$ (Einziger et al., 1992). The solid line represents parabolic law. From Figure 1, the time to complete matrix oxidation to $\mathrm{UO}_{2.4}$ was obtained as

$$
t_{2.4}(\text { years })=2.97 \times 10^{-13} \mathrm{e}^{26.6 \mathrm{kcal} / \mathrm{mol}-\mathrm{R}-\mathrm{T}}
$$

where " $t_{2.4}$ (years)" is the time in years for the complete oxidation of $\mathrm{UO}_{2}$ to $\mathrm{UO}_{2.4}$. From Figure 2, the growth kinetics of the oxidized width, w, was also determined as

$$
w=\left(2 k^{\prime} t\right)^{1 / 2}
$$

where $\mathrm{k}^{\prime}\left(\mu \mathrm{m}^{2} /\right.$ hour $)=1.04 \times 10^{8} \mathrm{e}^{-24.0(\mathrm{kcal} / \mathrm{mol}) / \mathrm{R} \cdot \mathrm{T}}$ (Einziger et al., 1992).

Although Equation 2 is experimentally determined, it is not empirical. It is known that diffusion of interstitial oxygen is rate limiting in lower oxidation. Equation 2 is a possible solution for governing differential equations pertaining to diffusion in a sphere. There can be several solutions, depending on the choice of unknown boundary conditions. The profile of interstitial oxygen concentration in the spherical grain can vary with these unknown boundary conditions. Equation 2 is a moving-boundary solution (Crank, 1975).

Equation 2 describes a conservative kinetics, because large scatters of experimental data in Figure 2 may imply that real kinetics are slower. Figure 2 shows a deviation from parabolic law as time elapses. It is difficult to quantify this behavior because information on the specific grain size for the measurement of "w" kinetics is not available and because the error bar is big. For large grains, parabolic laws may be observed during the testing period of Figure 2. On the other hand, smaller grains may not show parabolic laws. An actual slower kinetics with fewer experimental errors may explain the discrepancy of the two activation energies in Equations 1 and 2.

In addition, there is also an experimental uncertainty. The measured "w" kinetics was obtained from arbitrary sections of individual grains. This arbitrariness can also contribute to the deviation. Another experimental uncertainty includes the contribution of transverse cracks. In the beginning of oxidation, transverse cracks, initiated from grain boundaries, were observed (Thomas and Einziger, 1992). These cracks effectively decrease the averaged grain size. Concomitantly, oxidation is accelerated. Oxidation kinetics used for this 
Figure 1 Weight Changes of Oxidized Bare Fragments of Turkey Point Fuel at Temperatures From 250 to $360 \mathrm{C}$ (Einziger et al., 1992) (At temperatures above $280 \mathrm{C}$, the plateau at $\mathrm{O} / \mathrm{M}=2.4$ is very short and the oxidation proceeds rapidly to $\mathrm{U}_{3} \mathrm{O}_{8}$.)

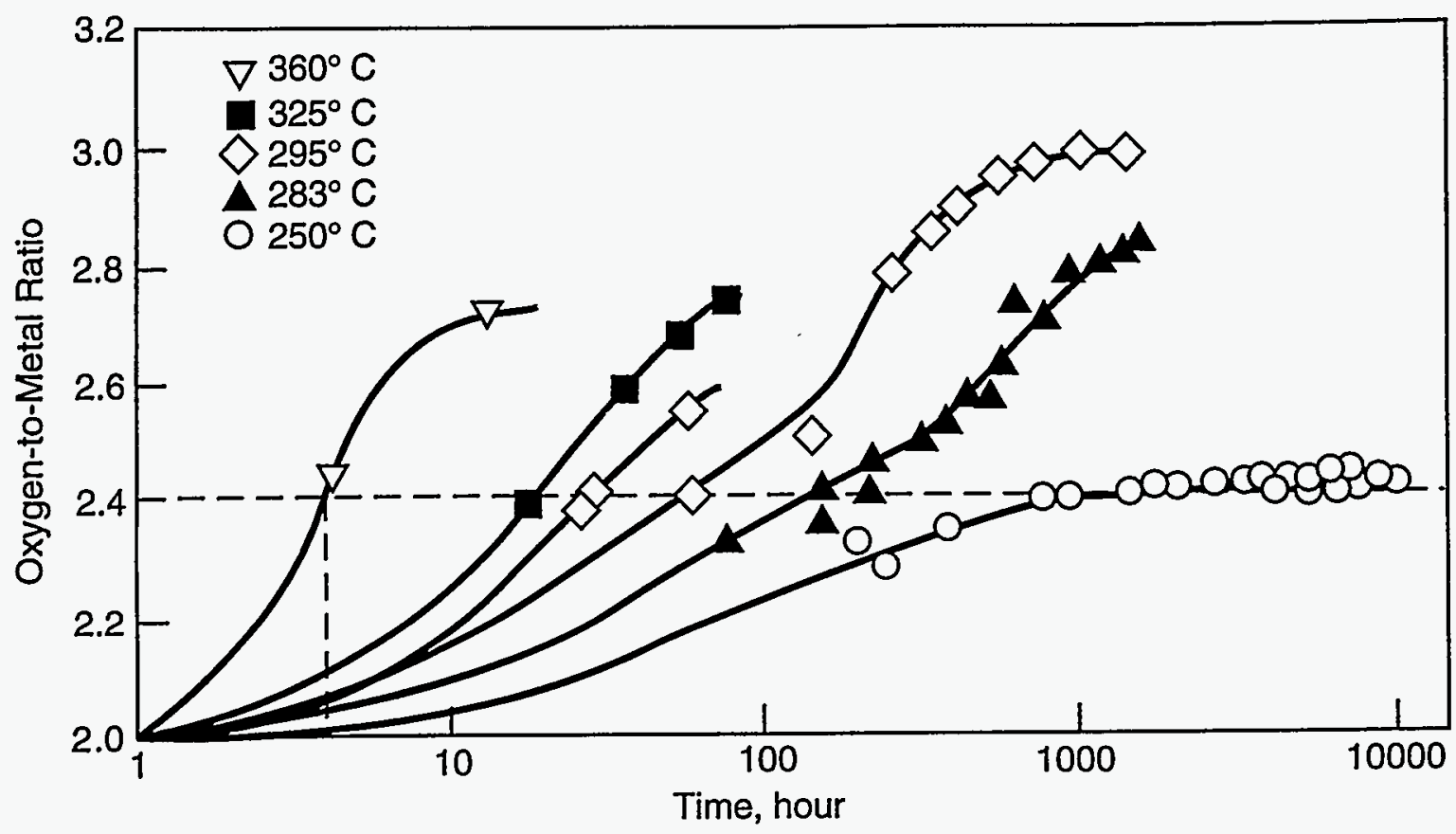

postulate showed a linear time law (Thomas and Einziger, 1992). However, these cracks were observed only near grain boundaries in large grains. Cracks initiated from the oxidation front were not observed in the grain interior. Therefore, the contribution of transverse cracks seems to be transitory and not important for a long period. 
Figure 2 Time Dependence of $\mathrm{U}_{4} \mathrm{O}_{9}$ Growth in Air-Oxidized LWR SF at $195 \mathrm{C}$ and $175 \mathrm{C}$ (Einziger et al., 1992)
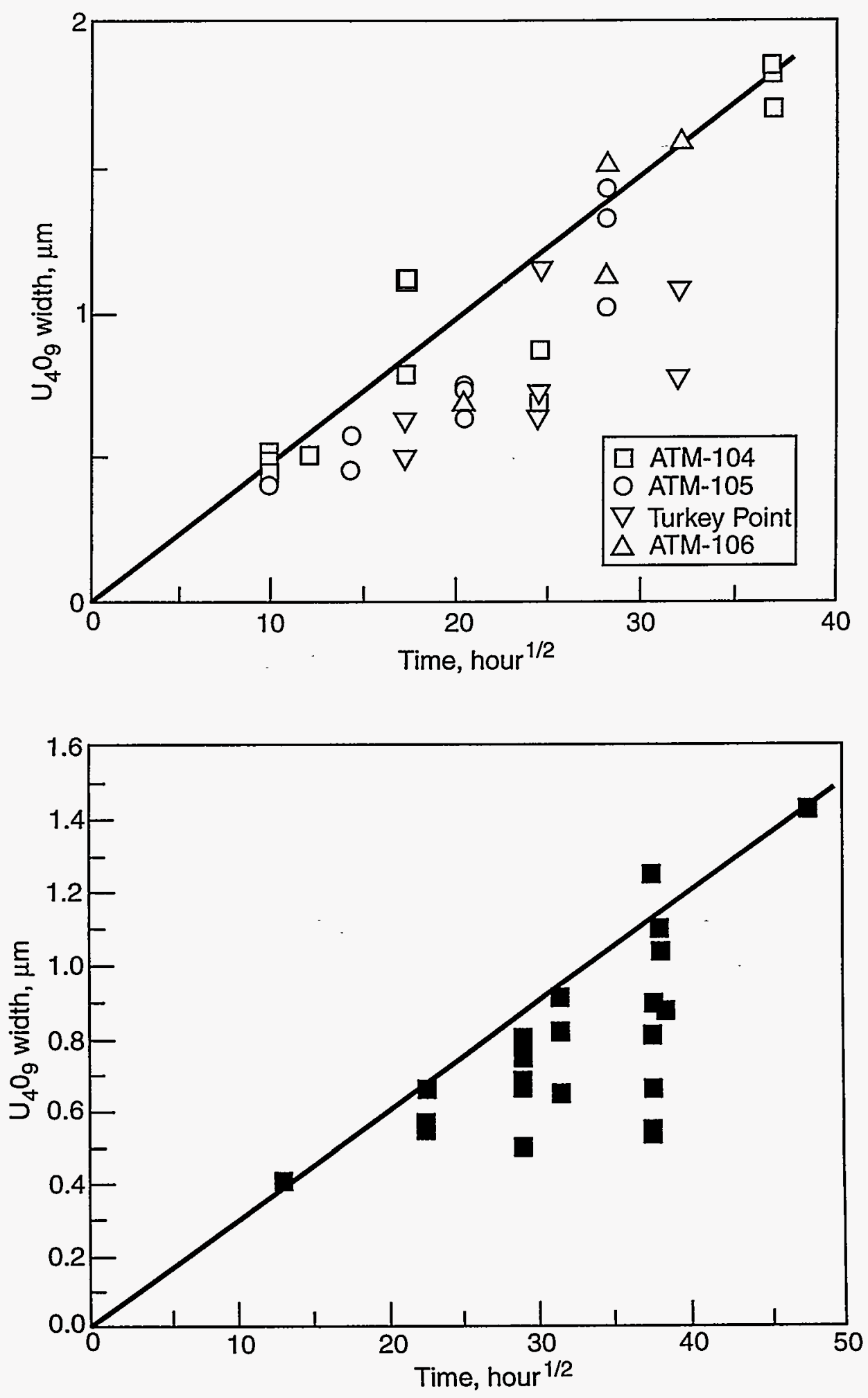
Table 1 shows calculated " $\mathrm{t}_{2.4}$ " values at various temperatures. If these calculated results are correct, matrix oxidation will be complete in 10,000 years at approximately $73.5 \mathrm{C}$ of repository temperature. However, uncertainties associated with the calculated results can be large due to experimental data uncertainties. For instance, the aforementioned $24.0 \mathrm{kcal} / \mathrm{mol}$ was extracted from the growth kinetics of the oxidized layer. Earlier transient data on weight changes gave $35.1 \mathrm{kcal} / \mathrm{mol}$ (Einziger and Buchanan, 1988), corresponding to the $24.0 \mathrm{kcal} / \mathrm{mol}$.

Table 1 Calculated Times To Complete the Oxidation of $\mathrm{UO}_{2}$ to $\mathrm{UO}_{2.4}$

\begin{tabular}{|c|c|c|c|c|c|c|}
\hline $\mathrm{T}(\mathrm{C})$ & 250 & 200 & 150 & 100 & 70 & 50 \\
\hline $\begin{array}{c}\mathrm{t}_{2.4} \\
\text { (years) }\end{array}$ & $3.3 \times 10^{-2}$ & $4.8 \times 10^{-1}$ & $1.3 \times 10$ & $9.1 \times 10^{2}$ & $2.1 \times 10^{4}$ & $2.3 \times 10^{5}$ \\
\hline
\end{tabular}

For grain boundary diffusion, the diffusion equation of the sphere model also can be used. The data of the time to grain boundary oxidation (Einziger and Buchanan, 1988) can be fitted to the relation of " $\left(\mathrm{D}_{\mathrm{g}} \mathrm{t} / \mathrm{b}^{2}\right)$ " equals approximately a constant (e.g., 1). In this relation, " $\mathrm{D}_{\mathrm{g}}$ " is the grain boundary diffusivity and " $b$ " is the radius of the averaged fuel particle. The leastsquare fitting of experimental data of Einziger and Buchanan (1988) to this relation results in an apparent activation energy of approximately $24.2 \mathrm{kcal} / \mathrm{mol}$. Using this value, grain boundary oxidation will be complete in a short period at various temperatures: 178 hours at $175 \mathrm{C}$; 15 years at $90 \mathrm{C}$; and 1,200 years at $50 \mathrm{C}$-all for particles of $0.17 \mathrm{~cm}$ in radius. However, the scatter of the data is significant. It should be noted that the matrix oxidation is frozen during the period of the grain boundary oxidation.

Many researchers pointed out that the activation energy of matrix diffusivity implies that mobile species are oxygen defects (interstitials) (Einziger, 1992; Einziger et al., 1992; Kofstad, 1972). However, the detailed structure of these defects may be more complicated (Kofstad, 1972). The extrapolation of high-temperature data to lower temperatures may not be valid, as for instance, if diffusion at lower temperatures takes place via other defects than oxygen interstitials. Other defects may include various impurities, dislocation network, or voids. The corresponding diffusivity is expected to be larger than the extrapolated value from the diffusivity of oxygen interstitials (Mansouri, 1995).

Up to this point, the traditional formulations on diffusion in the lower oxidation of SF have been summarized and evaluated. The traditional formulas were derived within the premise of idealized cases. The idealized cases are diffusion limits of single mobile species, in homogeneous system and in well-defined geometry. From this practice, the sphere model is the best choice in describing the diffusion-limited kinetics. Next, the reaction-limited formation of higher oxides such as $\mathrm{U}_{3} \mathrm{O}_{8}$ will be evaluated. Both $\mathrm{UO}_{2}$ and $\mathrm{SF}$ will be considered simultaneously. $\mathrm{UO}_{2}$ is simpler and better understood than SF. After the containment period of 300 to 1,000 years, SF may become more like $\mathrm{UO}_{2}$, if alpha radiation plays an important role in oxidation. Short-lived alpha-emitting radionuclides will decay away in this period. 


\subsection{Higher Oxidation}

The PNL group (Einziger et al., 1992) has understood that the values of Table 1 represent the times to initiate higher oxide formation in SF. The AECL group has also observed this type of Arrhenius relation for higher oxide formation in $\mathrm{UO}_{2}$ oxidation (Taylor et al., 1992b). The existence of this induction period has deeply interested many scientists who are attempting to avoid the higher oxide formation. Both the PNL group and the AECL group recognized some unusual behavior in $\mathrm{U}_{3} \mathrm{O}_{8}$ formation (on $\mathrm{SF}$ and $\mathrm{UO}_{2}$, respectively). In Figure 1 for SF, a time delay, " $\delta$, " was observed at the lowest temperature, $250 \mathrm{C}$. The schematic of the time delay is shown in Figure 3. The time delay is an additional time span, to the induction period to reach $(\mathrm{O} / \mathrm{U})=2.4$, before the onset of the higher oxide formation. The time delay is a period maintaining a plateau of $(\mathrm{O} / \mathrm{U})=2.4$ versus time. It has been noted because $\mathrm{U}_{3} \mathrm{O}_{8}$ presumably does not exist during the time delay.

Unfortunately, no accurate measurement of " $\delta$ " could be made, because " $\delta$ " was too short above $283 \mathrm{C}$ and too long below $225 \mathrm{C}$. This abrupt behavior leads us to consider that a nucleation process is involved. In fact, in $\mathrm{UO}_{2}$ oxidation, $\mathrm{UO}_{2}$ pellets showed $\mathrm{U}_{3} \mathrm{O}_{8}$ nucleation at cracks in $\mathrm{U}_{3} \mathrm{O}_{7}$, after the induction period, at $230 \mathrm{C}$ (Tempest et al., 1988). The nucleation needed a critical thickness of $\mathrm{U}_{3} \mathrm{O}_{7}$, ranging from $22 \mathrm{~nm}$ to $2 \mu \mathrm{m}$ (Taylor et al., 1980; Harrison et al., 1967). This critical thickness appears to be related to the time delay. If existent, the nucleation process is likely to be athermal (i.e., non-diffusional), such as martensitic nucleation, because the time to powdering of $\mathrm{UO}_{2}$ to $\mathrm{U}_{3} \mathrm{O}_{8}$ was almost independent of oxygen partial pressure (Taylor et al., 1992b).

There are other explanations for the time delay. Preferential grain-boundary oxidation can be responsible for the time delay. Grain boundaries may be oxidized to $\mathrm{U}_{3} \mathrm{O}_{8}$, preferentially during the time delay, without apparent changes in $(\mathrm{O} / \mathrm{U})$ ratio, 2.4. However,

Figure 3 Generalized Curve Representing the O/M State of SF as a Function of Oxidation Time (Einziger et al., 1992)

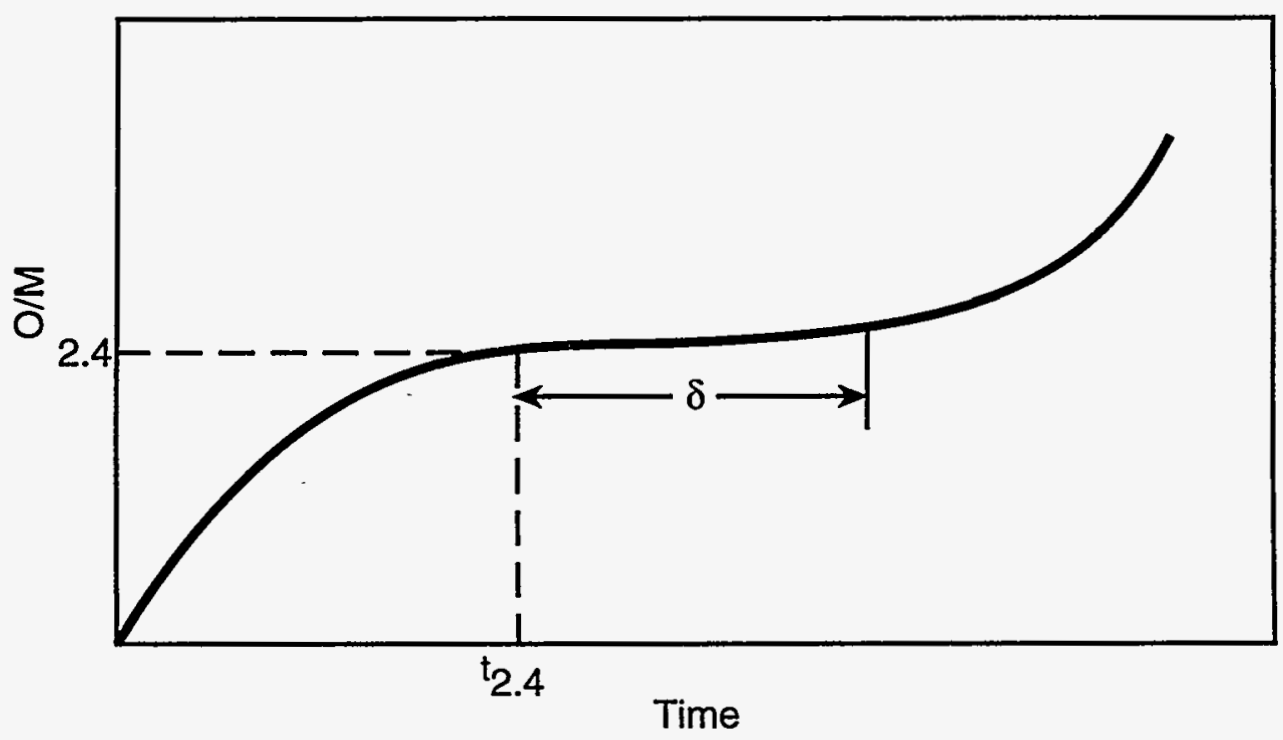


as previously mentioned, grain boundary oxidation (limited by grain boundary diffusion of oxygen) is much faster than the observed time delay. The other possibility is that oxygen for oxide formation may not be sufficient. An envelope calculation of equilibrium oxygen partial pressure over $\mathrm{UO}_{2+x(x<1)}$ showed that there is sufficient oxygen available for oxidation in the air environment.

Therefore, as the potential mechanism for the time delay, the nucleation process is evaluated here. Although heterogeneous nucleation is more likely (Thomas et al., 1989a; Tempest et al., 1988), formulas from homogeneous diffusional nucleation are adopted to simplify discussion. The conclusion drawn here can be extended to the cases of (a) the heterogeneous nucleation and (b) the non-diffusional athermal nucleation. The heterogeneous nucleation needs to add a scale factor to the energy barrier for homogeneous nucleation (Shewmon, 1969). The athermal nucleation simply involves more mathematical complications (Lin et al.; 1992). Additionally, similar formulas have been derived for nonclassical massive transformation (i.e., spinodal decomposition) (Cahn and Charles, 1965). In this case, the exponent in the formula below needs to be modified.

The driving force for the homogeneous and diffusional nucleation, " $\Delta \mathrm{G}_{\mathrm{v}}$, has been generally approximated to be $\left[-\Delta \mathrm{H}_{\mathrm{f}}\left(\mathrm{T}-\mathrm{T}_{\mathrm{E}}\right) / \mathrm{T}_{\mathrm{E}}\right]$ (Kingery et al., 1976; Sauthoff, 1976). (Alternatively, this can be $\left[-R T \ln \left(C_{\text {sup }} / C_{o}\right)\right]$, where " $C_{\text {sup }}$ " and " $C_{o}$ " are the concentration and the solubility limit of transforming species, respectively). In this equation, " $\Delta \mathrm{H}_{\mathrm{f}}{ }^{\prime \prime}$ is the transformation enthalphy; " $\mathrm{T}_{\mathrm{E}}$ " is the temperature of the boundary between equilibrium phases (the phase-boundary temperature). Inputs of other energies can be added to this equation, if necessary. The other energy inputs may include (a) radiation energy, (b) strain energy, or (c) chemical free energy associated with fission products or point defects.

The nucleation process is normally accompanied by an incubation time as $\mathrm{h} \mathrm{N}_{\mathrm{c}}{ }^{2} /\left(\mathrm{k} \mathrm{T} \mathrm{e}^{-\mathrm{Q} / \mathrm{R}-\mathrm{T}}\right)$ (Christian, 1965) or as $6 \mathrm{k} \mathrm{T} \mathrm{N}_{\mathrm{c}}{ }^{2} /\left(\beta^{*} \Delta \mathrm{G}_{\mathrm{c}}\right)$ for dilute supersaturation (Russel, 1968). $\mathrm{N}_{\mathrm{c}}=$ (2 N $\left.\Delta G_{c} / \Delta G_{v}\right)$ where $\Delta G_{c}=\left(16 \pi \gamma_{m}{ }^{3} M^{2}\right) /\left(3 \rho^{2} \Delta G_{v}{ }^{2}\right)$, and $\beta^{* \prime}=\left(4 \pi R_{c}{ }^{2}\right.$ a N $\left.C_{\text {sup }} D_{m}\right)$ where $R_{c}=\left(3 \Delta G_{c} /\left(4 \pi \gamma_{m}\right)\right)^{1 / 2}$. The "a" is the size of species for the new phase, " $D_{m}$ " is the species diffusivity, " $\gamma_{\mathrm{m}}$ " is the surface energy of the oxidized solid, " $\rho$ " is the density of the oxidized solid, and " $\mathrm{M}$ " is the molecular weight of the new phase formed. Then, the time delay (i.e., incubation time), becomes the forms of

$$
\delta \propto \frac{e^{\frac{Q}{R T}}}{T\left(T-T_{E}\right)^{6}}
$$

or 


$$
\delta \propto \frac{T e^{\frac{Q}{R T}}}{\left(\text { constant }+\left(T-T_{E}\right) / T\right)\left(T-T_{E}\right)^{2}}
$$

For the heterogeneous nucleation, the value of " $\Delta \mathrm{G}_{\mathrm{c}}$ " can vary from zero to the value for the corresponding homogeneous nucleation (Shewmon, 1969) in $t$. This means that the incubation time can be instantaneous until $\mathrm{T}$ approaches " $\mathrm{T}_{\mathrm{E}}$." Equations 3 and 4 were also evaluated for various values of the parameters involved. Depending on the choice of the parameters, including the scale factor in the energy barrier for nucleation, the calculated times can be on the order of 100 hours or shorter. The order of 100 hours appears to be the maximum time span at the plateau at temperatures above $250 \mathrm{C}$ in Figure 1. The experimental data base for the choice of these parameters is not available presently. Therefore, it is more realistic to discuss the functional behavior only. For this purpose, the conjectured formula from experiments is discussed with Equations 3 and 4.

Although the " $\delta$ " value could not be measured accurately, the dependence of " $\delta$ " on temperature has been conjectured empirically to have the functional form of $\delta=\delta_{0} \mathrm{e}^{\mathrm{Q} / \mathrm{R}-\mathrm{T}}$ from experimental observations (Stout and Leider, 1994; Einziger and Strain, 1986). The experimental work on defected cladding and splitting of the cladding after formation of $\mathrm{U}_{3} \mathrm{O}_{8}$ provides the following:

$$
t_{2.4}+\delta=t_{0} e^{\frac{Q}{R T}}
$$

where $t_{0}=1.56 \times 10^{-19}$ years and $Q=44.1 \mathrm{kcal} / \mathrm{mol}$.

Obviously, Equation 5 includes times for $\mathrm{U}_{3} \mathrm{O}_{8}$ growth and for splitting of the cladding, besides the nucleation time for $\mathrm{U}_{3} \mathrm{O}_{8}$. Diffusion-limited growth kinetics of $\mathrm{U}_{3} \mathrm{O}_{8}$ may show the relation of Equation 5 as shown in Equation 1. However, the nucleation process is likely to be involved because Figure 1 does not show the diffusional behavior for " $\delta$." The " $\delta$ " behavior was very abrupt in this temperature range, compared to the Arrhenius behavior. Table 2 shows the sensitivity of terms in the time delay around " $\mathrm{T}_{\mathrm{E}}$ " (Equations 3 and 4 ). Of course, at temperatures close to " $T_{E}$," the driving force for new phase formation becomes minimal, resulting in a very long time delay. Functionally, Equation 3 or 4 can represent this abnormal behavior. Equations 3 and 4 have additional T-dependent terms to the Arrhenius relation of " $\mathrm{e}^{\mathrm{Q} / \mathrm{R}-\mathrm{T}}$." This additional term is likely to lead to the abrupt behavior of the temperature dependence of " $\delta$." The activation energy, $44.1 \mathrm{kcal} / \mathrm{mol}$ in Equation 5, may include the energy for the nucleation. For a reference, the activation energy for the diffusionlimited growth of $\mathrm{U}_{3} \mathrm{O}_{8}$ in $\mathrm{UO}_{2}$ is in the range of $30 \mathrm{kcal} / \mathrm{mol}$ for irradiated and unirradiated CANDU (Canadian Deuterium-Natural Uranium Reactor) fuel (Taylor et al., 1992b). 
Table 2 Calculated Relative Values of Time Delay

\begin{tabular}{|c|c|c|c|c||}
\hline \hline$T-T_{E}(C)$ & $\begin{array}{c}T(C) \text { at } T_{E} \\
=250 C\end{array}$ & $\left(T_{E}-T\right)^{-6}$ & $\left(T_{E}-T\right)^{-3}$ & $\begin{array}{c}\text { Q/R-T } \\
\left(\begin{array}{c}\text { values from } \\
\text { Equation 2) }\end{array}\right.\end{array}$ \\
\hline 0 & 250 & $\infty$ & $\infty$ & $\tau_{C}$ \\
\hline 1 & 251 & $\tau_{A}$ & $\tau_{B}$ & $\tau_{C}$ \\
\hline 10 & 260 & $10^{-6} \tau_{A}$ & $10^{-3} \tau_{B}$ & $2 \tau_{C}$ \\
\hline 100 & 350 & $10^{-12} \tau_{A}$ & $10^{-6} \tau_{B}$ & $60 \tau_{C}$ \\
\hline 150 & 400 & $9 \times 10^{-14} \tau_{A}$ & $4 \times 10^{-7} \tau_{B}$ & $220 \tau_{C}$ \\
\hline 200 & 450 & $2 \times 10^{-14} \tau_{A}$ & $2 \times 10^{-7} \tau_{B}$ & $1,110 \tau_{C}$ \\
\hline
\end{tabular}

Values from Equations 3 and 4 in long-term performance assessments are likely to be longer than those from Equation 5 because the aforementioned additional T-dependent terms effectively increase the $Q$ value. Therefore, the extrapolated time delay from Equation 5, $1.1 \times 10^{4}$ years at $150 \mathrm{C}$, would be a conservative value; $\mathrm{U}_{3} \mathrm{O}_{8}$ is unlikely to form at temperatures below $150 \mathrm{C}$ for $10^{4}$ years. In $\mathrm{UO}_{2}$ oxidation studies, as another example, similar Arrhenius relations were made from data on times to reach various stages of formation and growth of $\mathrm{U}_{3} \mathrm{O}_{8}$ (Taylor et al., 1992b).

The above evaluation assumes that higher oxides are unstable thermodynamically at $T<T_{E}$ ( $T_{E}$ is possibly around $250 \mathrm{C}$ ). In the U-O phase diagram (Taylor et al., 1991; Thomas et al., 1989a), however, higher oxides are stable at $\mathrm{T}<$ about $250 \mathrm{C}$. Therefore, the hypothesis to support Equations 3 and 4 needs evidence that the chemistry of fission products or the radiation field in SF possibly modifies the stable regimes of various U-based oxides in the phase diagram of unirradiated $\mathrm{UO}_{2}$. This modification will lead to unstable higher oxides at $T<T_{E}$ in SF. It is generally accepted that the altered chemistry by rare-earth elements from pure $\mathrm{UO}_{2}$ destabilizes higher oxides thermodynamically (Thomas et al., 1993). Rareearth elements in SF are produced during the fission process.

Alternatively, the displacement damage by alpha particles and recoil may destabilize higher oxides. The displacement damage makes $\mathrm{U}_{3} \mathrm{O}_{8}$ amorphous, and subsequently the amorphous phase decomposes to $\mathrm{U}_{4} \mathrm{O}_{9}$ (Matzke, 1982, 1976; Naguib and Kelly, 1975). $\mathrm{U}_{3} \mathrm{O}_{8}$ may not form until the temperature is high enough to recover from the radiation damage. There is another indirect indication that radiation effects play a role. In independent tests of British fuels, radiation effects were observed at $350 \mathrm{C}$, and disappeared at 425 to $500 \mathrm{C}$ (Schmets, 1963). This trend is consistent with the expectation of the initial displacement damage and subsequent recovery as temperature increases (Matzke, 1982).

The above postulate, that a threshold temperature, " $T_{E}$," exists, assumes that " $T_{E}$ " values do not change in a repository period. Because " $\mathrm{T}_{\mathrm{E}}$ " values. are normally measured in laboratory tests, this assumption may not be valid. Therefore, the $" \mathrm{~T}_{\mathrm{E}}$ " values in a repository period are 
discussed here. Hypothetical activities of higher oxides in equilibrium can be expressed simply by "e- $e^{-\Delta G / R T}$. " $\Delta G_{f}$ " is the free energy of higher oxide formation. Table 3 tabulates the relative values of these hypothetical activities in laboratory test periods for chosen values of $\Delta \mathrm{G}_{\mathrm{f}}=48$ and $96 \mathrm{kcal} / \mathrm{mol}$. These " $\Delta \mathrm{G}_{\mathrm{f}}$ " values are for chemical transformation and potential fusion for higher oxides (Taylor et al., 1992a; Matzke, 1982). The hypothetical activities represent the amounts transformed in laboratory test periods. This table suggests that the amounts of higher oxides formed, for instance at $150 \mathrm{C}$, would be very small in the longer test period, if higher oxides formed completely at $250 \mathrm{C}$ in this period. Consequently, laboratory data, " $\mathrm{T}_{\mathrm{E}}$," can be regarded as true equilibrium " $\mathrm{T}_{\mathrm{E}}$ " over a very long period.

Table 3 Calculated Relative Values of Hypothetical Activities to " $C_{B}$ a" of Equilibrium Concentration

\begin{tabular}{|c|c|c||}
\hline$T \cdot(\mathrm{C})$ & $\Delta \mathrm{G}_{\mathrm{f}}^{\mathrm{b}}=48 \mathrm{kcal} / \mathrm{mol}$ & $\Delta \mathrm{G}_{\mathrm{f}}=96 \mathrm{kcal} / \mathrm{mol}$ \\
\hline 280 & $4.1 \times 10^{-3}$ & $1.6 \times 10^{-5}$ \\
\hline 250 & $3.4 \times 10^{-4}$ & $1.1 \times 10^{-7}$ \\
\hline 150 & $6.2 \times 10^{-9}$ & $3.8 \times 10^{-17}$ \\
\hline 100 & $3.0 \times 10^{-12}$ & $9.0 \times 10^{-24}$ \\
\hline
\end{tabular}

a " $\mathrm{C}_{\mathrm{B}}$ " is the value at $360 \mathrm{C}$.

b " $\Delta \mathrm{G}_{\mathrm{f}}$ " values take into account chemical transformation and potential fusion from radiation (Taylor, 1992a; Matzke, 1982).

The above analyses of kinetics and of equilibrium postulate the potential existence of a very long time delay before higher oxide formation. This postulate needs further support from quantitative experimental data. Such data may include the following:

(a) more " $\mathrm{T}_{\mathrm{E}}$ " values. Earlier work in LWR SF oxidation (Thomas et al., 1989b) shows $\mathrm{U}_{3} \mathrm{O}_{8}$ formation from $\mathrm{U}_{4} \mathrm{O}_{9}$ at 150 to $190 \mathrm{C}$. Some pressurized-water reactor (PWR) and boiling-water reactor (BWR) oxidized $\mathrm{SF}$ matrices to $\mathrm{U}_{3} \mathrm{O}_{8}$ at $230 \mathrm{C}$ in less than 4,000 hours (Campbell et al., 1989a);

(b) processes of nucleation and growth (e.g., homogeneous or heterogeneous nucleation, or detection limit of oxidized phase); and

(c) understandings of the effects of radiation or fission-product chemistry.

Nevertheless, it should be noted that aqueous conditions can exist at YM. Under aqueous conditions, the higher oxide formation will be facilitated even at lower temperatures (Wronkiewicz et al., 1992; Taylor et al., 1992a). 
Up to this point, in this section, the author has evaluated the possibility that a threshold temperature for higher oxide formation exists. The nucleation process has been considered a potential mechanism for the existence of a threshold temperature. This interpretation assumes that the chemical alteration by fission products or the radiation field destabilizes higher oxides at repository temperatures.

Finally in this section, $\mathrm{U}_{3} \mathrm{O}_{8}$ behavior will be discussed. Regarding the amorphization of higher oxide, amorphous higher oxides may exist in a fraction at $(\mathrm{O} / \mathrm{U}) \leq 2.4$. It has been reported that $\mathrm{U}_{3} \mathrm{O}_{8}$ may coexist with $\mathrm{U}_{4} \mathrm{O}_{9}$ at 200 to $250 \mathrm{C}$ (Campbell et al., 1989a; Thomas et al., 1989b) in SF oxidation. $\mathrm{U}_{3} \mathrm{O}_{8}$ may also coexist with $\mathrm{U}_{4} \mathrm{O}_{9}$ at $(\mathrm{O} / \mathrm{U})=2.4$ in $\mathrm{UO}_{2}$ oxidation (Shiba, 1975). Substantial amounts of $\mathrm{U}_{3} \mathrm{O}_{8}$ are believed to form at $(O / U)=2.42$, at $360 \mathrm{C}$ in SF oxidation (Boase and Vandergraaf, 1977). Discontinuous cracks observed along grain boundaries at 200 to $250 \mathrm{C}$ are possibly from the volume expansion associated with $\mathrm{U}_{3} \mathrm{O}_{8}$. Therefore, the potential existence of amorphous $\mathrm{U}_{3} \mathrm{O}_{8}$ at $(\mathrm{O} / \mathrm{U}) \leq 2.4$ cannot be ruled out. For the composite formation, $(\mathrm{O} / \mathrm{U})=2.4$ may provide the portion of amorphous $\mathrm{U}_{3} \mathrm{O}_{8}$ from a factor of 0.0 to over 0.3 .

Alternatively, the $\mathrm{U}_{3} \mathrm{O}_{8}$ phase is still likely to be absent at $250 \mathrm{C}$. It may not be unusual that the non-stoichiometry extends from $(\mathrm{O} / \mathrm{U})=2.25$ (equivalent to $\mathrm{U}_{4} \mathrm{O}_{9}$ ) to 2.4 (Kofstad, 1972). If $\mathrm{U}_{3} \mathrm{O}_{8}$ phase is present along grain boundaries, the stress associated with $\mathrm{U}_{3} \mathrm{O}_{8}$ formation will be very high (see next section). This can lead to the total disintegration of grain boundaries. However, in experiments, only discontinuous cracks along grain boundaries have been reported (Einziger et al., 1992).

Regarding the growth of higher oxides, the apparent kinetics of $\mathrm{U}_{3} \mathrm{O}_{8}$ formation are faster than those of lower oxides at 320 to $380 \mathrm{C}$ (Harrison et al., 1967). However, the activation energies (Harrison et al., 1967) and the temperature-dependent behavior of the kinetics (Campbell, 1989b) suggest a crossover of the two kinetics at lower temperatures. The growth kinetics of $\mathrm{U}_{3} \mathrm{O}_{8}$ are likely to be slower than those of $\mathrm{U}_{4} \mathrm{O}_{9}$, in a very long period at lower temperatures. Therefore, it may take a long time to complete $\mathrm{U}_{3} \mathrm{O}_{8}$ formation at lower temperatures, even if $\mathrm{U}_{3} \mathrm{O}_{8}$ is nucleated. AECL data (Taylor et al., 1992b) partly support this postulate. The data show times for three different oxidation stages (i.e., detection limit, minor quantity, and powder formation). The growth time from detection limit to powder formation is the growth time. This growth time varies in a wide range of time period, suggesting long growth times.

\section{FRACTURE}

In the previous sections, oxidation properties of SF have been evaluated. An important consequence of SF oxidation in TSPA is the fracture of matrices and grain boundaries of SF. The fracture is likely to result in fast release of radionuclides. In this section, the fracture process associated with SF oxidation will be evaluated. The SF matrix contracts approximately 3 percent by the formation of $\mathrm{U}_{4} \mathrm{O}_{9}$, or $\mathrm{U}_{3} \mathrm{O}_{7}$ (Thomas et al., 1989b). On the other hand, volume expansion of approximately 35.8 percent (Thomas et al., 1989b) is expected upon higher oxide formation. Because of this volume change, higher oxide 
formation results in SF powdering; lower oxide formation results in discontinuous intergranular fractures.

The procedures for quantifying the fracture process will be discussed. First, it will be verified that the stress generated by the differential volume change is sufficient to cause the fracture. Second, the total surface area created by the fracture will be quantified. As a firstorder approximation, isotropic, homogeneous, and elastic media are assumed. Under this assumption, the stress (or pressure) developed by the linear volume change is given by McClintock and Argon (1966) as follows:

$$
\sigma=\frac{E}{(1-2 v)} \frac{\Delta V}{3 V}
$$

where " $(\Delta \mathrm{V} / \mathrm{V})$ " represents the volume expansion (or contraction), " $\mathrm{E}$ " is Young's modulus, and " $\nu$ " is Poisson's ratio. More rigorous formulas for various geometries are available in many text books. Table 4 shows calculated and experimentally measured fracture strength for lower oxide formation. The calculated values are sufficiently large to cause grain boundary fractures. The overestimate is likely to come from many sources, which are discussed later in this section. During higher oxidation, the stress is so high that powder forms. Powder may form both by intergranular fracture and transgranular fracture.

It is difficult to determine the area of fractured surfaces quantitatively. As mentioned previously, Stout and his coworkers' formulation (1993a,b) (see Section 2.1) may be a basis for this assessment of the fractured surface area. Unfortunately, Stout and his coworkers have not determined the rate-limiting process among various processes they proposed. The proposed processes include phase transformation, heat generation, deformation, transport, and defect generation. Their proposal is so general, without supports from experimental data, that a numerical evaluation of the proposal is not possible. In reality, only one or two among all those processes is likely to govern the oxidation. Once these one or two processes are determined, numerical evaluation will be possible. Although quantitative contributions of all these processes to the real fracture process are not known, strain energy is believed to be the major cause of the fracture process. The rest of the energies associated with these processes, although they can be dominant, are likely to be dissipated as heat.

The analysis here uses earlier data on the use of strain energy to create new surface areas in glass (Martin, 1985). It also assumes isothermal conditions. Therefore, the estimate here is an upper limit, primarily because the glass fracture does not involve the phase transformation, as SF does. The phase transformation may consume elastic energy also. Equation 7 describes the elastic strain energy stored per unit volume.

$$
\epsilon=\frac{E}{2(1-2 v)}\left(\frac{\Delta V}{3 V}\right)^{2}
$$


Table 4 Differential Stress Caused by $\mathrm{UO}_{2}$ Oxidation

\begin{tabular}{||c|c|c|c||c|c||}
\hline \multirow{2}{*}{ Item } & \multicolumn{5}{|c||}{ Property } \\
\cline { 2 - 6 } & $\mathrm{E}(\mathrm{MPa})^{\mathrm{a}}$ & $\nu^{\mathrm{a}}$ & $\begin{array}{c}\text { Fracture } \\
\text { Strength } \\
(\mathrm{MPa})^{\mathrm{a}}\end{array}$ & \multicolumn{2}{|c|}{$\begin{array}{c}\text { Calculated } \sigma(\mathrm{MPa}) \\
\text { Equation 6 for Three } \\
\text { Values of } \Delta \mathrm{V} / \mathrm{V}(\%)\end{array}$} \\
\hline Values & 145,000 & 0.302 & $16 \sim 42^{\mathrm{b}}$ & $\Delta \mathrm{V} / \mathrm{V}=1$ & $\sigma=1,219$ \\
\hline $\mathrm{T}(\mathrm{C})$ & $0 \sim 1,000$ & -- & -- & 3 & 3,656 \\
\hline Reference & $\begin{array}{c}\text { Schackelford, } \\
1992\end{array}$ & $\begin{array}{c}\text { Schackelford, } \\
1992\end{array}$ & $\begin{array}{c}\text { Belle, } \\
1961\end{array}$ & 35.8 & 43,630 \\
\hline
\end{tabular}

a The manufacturing process of $\mathrm{UO}_{2}$ was not specified for "E" and " $\nu$," whereas fracture strengths were for various manufacturing processes of $\mathrm{UO}_{2}$.

${ }^{b}$ Modulus of rupture.

The total strain energy is " $\epsilon$ " times the time-dependent oxidized volume (for instance, Equation 2 can be used to determine the volume at various times). If a fraction of this energy for creating new surface areas is known, the new surface areas can be calculated. Table 5 shows results of a sample calculation. The table suggests a large increase in the surface area for the total conversion of $\mathrm{SF}$ to $\mathrm{U}_{4} \mathrm{O}_{9}$ (grain boundary fracture) or to $\mathrm{U}_{3} \mathrm{O}_{8}$ (matrix fracture). The new surface area is obtained by dividing the fraction of the strain energy used in fracture by the specific surface energy associated with fracture.

Table 5 also shows that volume contraction by 3 percent will result in 100-percent opening of grain boundaries. Experimental results in $\mathrm{U}_{4} \mathrm{O}_{9}$ showed both (a) discontinuous opening of grain boundaries (Einziger et al., 1992) and (b) 100-percent opening of grain boundaries (Einziger and Strain, 1986). This overestimate may come from several uncertainties. Transgranular fractures as observed in the transient period (Thomas and Einziger, 1992) could have consumed part of this energy. Strain could have been localized at grain boundaries; consequently, smaller deformed volume from the localization stores less elastic energy. Finally, the energy conversion factor (a fraction of the strain energy), 4 percent in Table 5, could have been an overestimate in SF.

The size of fractured particles was also obtained from the calculated surface area, assuming spherical particles. The calculated size is approximately $3 \times 10^{-6} \mathrm{~cm}$ (note that this is the colloidal size). Most experimental results show transgranular fractures during $\mathrm{U}_{3} \mathrm{O}_{8}$ formation. The intercrack size has been reported in a multimicrometer (Stacy and Goode, 1978), a micrometer, or a submicrometer (Tempest et al., 1988; Einziger and Strain, 1986), except one in an order of $10^{-6} \mathrm{~cm}$ (Thomas et al., 1989b). (Data of $10^{-6} \mathrm{~cm}$ need to be confirmed, because of contamination in the experiments.) Therefore, the calculation appears to overestimate the real particle size. Considering that detailed microstructure down to 
Table 5 Calculated ${ }^{a-g}$ Surface Areas Associated With Fractures in 100-Percent Oxidized SF

\begin{tabular}{|c|c|c|c||}
\hline$\Delta \mathrm{V} / \mathrm{V}(\%)$ & $\epsilon\left(\mathrm{erg} / \mathrm{cm}^{3}\right)$ & $\begin{array}{c}\text { Surface Area } \\
\text { Increase } \\
\text { (Factor) }\end{array}$ & $\begin{array}{c}\text { Fracture } \\
\text { Path }\end{array}$ \\
\hline 1 & $2.03 \times 10^{7}$ & 0.71 & grain boundary \\
\hline 3 & $1.83 \times 10^{8}$ & 1 (all) & grain boundary \\
\hline 35.8 & $2.60 \times 10^{10}$ & 620 & matrix \\
\hline
\end{tabular}

Parameters Used in the Calculations:

a A spherical particle was assumed with a radius of $0.055 \mathrm{~cm}$ (an arbitrary value between 0.025 and $0.07 \mathrm{~cm}$ (Einziger and Buchanan, 1988)).

b A spherical grain was assumed with a radius of $1.75 \times 10^{-3} \mathrm{~cm}$ (Einziger and Buchanan, 1988).

c Four percent of the calculated strain energy was used in creating new surfaces (Martin, 1985).

d Surface energy of $1,000 \mathrm{erg} / \mathrm{cm}^{2}$ was used; and one-third of the surface energy was assumed to be the high-angle grain boundary energy (Swalin, 1972).

e For grain boundary fracture, the increase factor of surface area is in reference to grain boundary area.

f Values of other parameters were taken from Table 4.

$g$ Because many steps are involved in oxidation, the percentages of volume changes given here are for unirradiated $\mathrm{UO}_{2}$. Minor corrections can be made for various precursory oxides.

$10^{-6} \mathrm{~cm}$ was not examined in these experiments; further experimental work is necessary before the conclusion that the present calculation is an overestimate. If the calculation is an overestimation, the error likely arises from the aforementioned uncertainties.

Real-life repository conditions may be different from laboratory conditions. For instance, temperature may change. Consequently, the analysis may become more complicated.

Nevertheless, natural analogue studies provide supporting evidence of these microcracks. The uraninite exposed to oxidizing waters developed microcracks and micropores (Finch and Ewing, 1990). The calculations conducted in this section regarding fracture properties agree qualitatively with experimental observations. Other causes for the internal fracture, such as helium buildup, are not considered here.

\section{RADIONUCLIDE RELEASES}

This section summarizes how oxidation and fracture processes affect radionuclide releases from the SF matrix. In saturated environments, SF oxidation may be a precursory step to the matrix dissolution of SF under oxidizing conditions. Scientists have understood that oxidized thin layers formed during dissolution are responsible for the subsequent matrix dissolution of 
SF (Shoesmith and Sunder, 1991). The matrix dissolution of SF will govern the release of high-solubility radionuclides such as C-14, Tc-99, I-129, or Cs-135. Therefore, preoxidation before dissolution does not affect dissolution behavior under oxidizing environments (Steward, 1995; Gray et al., 1993). However, when $\mathrm{UO}_{3}$ forms during preoxidation, the dissolution rate increases by a factor of 1,000 at $75 \mathrm{C}$ in carbonate solutions (Steward, 1995). Presently, the reason for this increase in the dissolution rate is unknown.

For low-solubility radionuclides such as Pu- $(239+240)$ or Am- $(241+243)$, the oxidized phase of the matrix may increase the solubility limits of these radionuclides. The increased solubility limits can, in turn, increase the extent of supersaturation, if existent. Thin-layer oxidation during SF dissolution under oxidizing conditions is expected to result in highsolubility limits of radionuclides regardless of preoxidation. In reality, though, preoxidation increases concentrations of dissolved actinides more than SF without preoxidation at 25 and $85 \mathrm{C}$ in J-13 well water, by at least a factor of 10 (Wilson, 1990). Low-solubility radionuclides are also known to form colloids, under static conditions (Ahn, 1995; Wilson, 1990) or under dripping groundwater conditions (Ahn, 1995; Finn et al., 1994; Wronkiewicz et al., 1992). Up to now, colloid formation has been reported only under oxidizing conditions.

Under saturated conditions, the fracture-induced increase of surface area will increase radionuclide releases. For high-solubility radionuclides, radionuclide releases will increase in proportion to the increase of surface area, on a first-order approximation. On the other hand, for low-solubility radionuclides, the amount of colloids will increase also, with the increase of surface area. Similar effects may arise from preferential oxidation of grain boundaries. Preoxidized grain boundaries may be dissolved quickly, exposing a large surface area. Recent DOE experimental results suggest that individual grains may be exposed when SF is immersed in groundwater with preoxidation to lower oxides (Lawrence Livermore National Laboratory, 1995).

In the above discussion, the author has considered the effects of preoxidation on subsequent dissolution of SF in aqueous environments. There are more direct effects of dry oxidation on radionuclide release. Some radionuclides can be released by solid-state diffusion within the SF matrix. These radionuclides involve C-14, Cl-36, Tc-99, I-129, and Cs-135. Because their atomic (or ionic) sizes are smaller than those of actinides, their solid-state diffusion may not be negligible. In general, the smaller the atomic size, the faster the solid-state diffusion. The size becomes bigger as the atomic number increases. Under repository conditions, C-14 behavior has only been evaluated a little, whereas the rest of the aforementioned radionuclides have been mostly studied at high temperatures during reactor operation.

C-14 releases have been separately analyzed and modeled during SF oxidation in dry environments (Ahn, 1994). For details on this C-14 behavior, the reader is referred to Ahn (1994) and related papers such as those by Codell (1993) or Van Konynenburg (1994). Summarizing the author's work, higher oxide formation may release C-14 from bare SF, significantly for 10,000 years in terms of its inventory, under anticipated dry conditions. However, there are uncertainties about the extent of this higher oxidation and about C-14 
For I-129, the role of the surface area is unclear. The I-131 (I-129, I-131, and I-135 are expected to behave similarly in diffusion) radionuclides were adsorbed on the surface of irradiated $\mathrm{UO}_{2}$ at room temperature and not released to air (Shiba, 1975); evaporation of I131 was negligible at near-room temperatures. Therefore, I-129 is likely to be released by groundwater flow after the diffused-out I-129 is dissolved in subsequent aqueous environments.

I-131 was released in significant amounts during the annealing of irradiated $\mathrm{UO}_{2}$ in the temperature range of $1,000 \mathrm{C}$. However, at $250 \mathrm{C}$, the releases came from the surface desorption only, as I-131 mobility in the matrix became negligible (Shiba, 1975). Table 6 shows small values of diffusivities of fission gases at temperatures of 100 to $200 \mathrm{C}$. The amount of $\mathrm{I}-131$ gas released increases as the ratio of $(\mathrm{O} / \mathrm{U})$ increases. Amorphization can further increase fission gas releases (Ball and Grimes, 1992). For complete I-129 releases from about $10 \mu \mathrm{m}$ grain in $10^{4}$ years, I-129 diffusivity should be about $3 \times 10^{-18} \mathrm{~cm}^{2} / \mathrm{sec}$. This estimation used a formula for diffusion in a sphere (Crank, 1975).

The diffusion equation in a sphere is (Crank, 1975)

$$
\frac{M_{t}}{M_{\infty}}=1-\frac{6}{\pi^{2}} \sum\left(\frac{1}{n^{2}} e^{-D_{m} n^{2} \pi^{2} t / a^{2}}\right)
$$

where " $M_{t}$ " and " $M_{\infty}$ " are the amounts of oxidized phases, at time " $t$ ", and at an infinite time, respectively; " $D_{m}$ " is the matrix diffusivity; and " $a$ " is the radius of the averaged fuel grain. In this sphere model, the time to complete the matrix oxidation is obtained by the relation of "( $\left.D_{m} t / a^{2}\right)$ " equals approximately a constant (e.g., 1) (Crank, 1975).

Table 6 shows that diffusivity in oxidized $\mathrm{UO}_{2+x(x<1)}$ is smaller than the diffusivity of $3 \times 10^{-18}$ $\mathrm{cm}^{2} / \mathrm{sec}$., suggesting I-129 will not be released completely. More data are necessary to confirm this conclusion because it is possible that I-129 diffusivities can increase. For instance, amorphization o1 higher oxidation may increase diffusivities (Shiba, 1975); burnup can increase diffusivity, as shown in Table 6. Additionally, fast diffusion mechanisms may operate at lower temperatures. Impurities, dislocations, or clusters may increase the lower temperature diffusivity of I-129 (Mansouri, 1995; Belle, 1961).

Among the various possibilities of fast solid-state diffusion, the author selects diffusion in the $\mathrm{U}_{3} \mathrm{O}_{8}$ matrix as an example. Xe-133 diffusivity has been measured in the higher oxide (Lindner and Matzke, 1959). Xe-133 diffusivity is presumably slower than or closer to the diffusivities of $\mathrm{Cl}-36, \mathrm{Tc}-99, \mathrm{I}-129$, and $\mathrm{Cs}-135$, because the atomic number of Xe-133 is bigger than or closer to the rest. Therefore, Xe-133 diffusivity can be used as a conservative approximation $-\mathrm{D}_{\mathrm{m}}$ for Xe-133 $\simeq 1.5 \times 10^{-10}\left(\mathrm{~cm}^{2} / \mathrm{sec}\right.$.) $\mathrm{e}^{-18.6 \mathrm{kca} /(\mathrm{mol}-\mathrm{K}) / \mathrm{RT}}$ (from data by Lindner and Matzke, 1959). With this diffusivity at 200 and $100 \mathrm{C}$, all Xe-133 will be released from fractured $\mathrm{U}_{3} \mathrm{O}_{8}$ particles $(\sim 1 \mu \mathrm{m})$ within 1,000 and 10,000 years, respectively. Recent measurements show that similar conclusion may be made even in lower oxides, if shortcircuit diffusion paths (such as dislocations) are abundant (Mansouri, 1995). 
Table 6 Diffusivities of Fission Gases ${ }^{\text {a-b }}$

\begin{tabular}{|c|c|c|c|c|c|}
\hline $\begin{array}{c}\mathrm{D}\left(\mathrm{cm}^{2} / \mathrm{sec} .\right) \\
\{\mathrm{D} \text { values at } 100 \mathrm{C}\} \\
\text { and } \\
<\mathrm{D} \text { values at } 200 \mathrm{C}>^{\mathrm{c}}\end{array}$ & $\begin{array}{l}\text { Temp. } \\
\text { (C) }\end{array}$ & Materials & $\begin{array}{c}\text { Diffusion } \\
\text { Species }\end{array}$ & Remarks & Ref. \\
\hline$(2.8 \sim 4.1) \times 10^{-13}$ & 1500 & $\mathrm{UO}_{2}$ & I-135 & $\begin{array}{l}\text { Single } \\
\text { crystal }^{1}\end{array}$ & $\mathrm{~A} 1$ \\
\hline$(0.6 \sim 2.8) \times 10^{-13}$ & 1500 & $\mathrm{UO}_{2}$ & $\mathrm{Xe}-133$ & Plate & A2 \\
\hline $\begin{array}{c}6.6 \times 10^{-6} \\
\times \mathrm{e}^{-71,700 \mathrm{ca} / \mathrm{RT}} \\
\left\{1.2 \times 10^{-47}\right\}<8.0 \times 10^{-39}>\end{array}$ & $\begin{array}{l}700- \\
1750\end{array}$ & $\mathrm{UO}_{2}$ & $\mathrm{Xe}-133$ & Powder & $\mathrm{A} 2$ \\
\hline $\begin{array}{c}2.0 \times 10^{-8} \\
\times \mathrm{e}^{-48,900 / \mathrm{RT}} \\
\left\{6.8 \times 10^{-37}\right\}<7.1 \times 10^{-31}>\end{array}$ & $\begin{array}{l}700- \\
1750\end{array}$ & $\mathrm{UO}_{2}$ & $\mathrm{Xe}-133$ & Powder & A2 \\
\hline $10^{-18} \sim 10^{-17}$ & 560 & $\begin{array}{c}\mathrm{UO}_{2+\mathrm{x}(x<1)} \\
(\mathrm{x}=0.02,0 . \\
12,0.67)\end{array}$ & $\begin{array}{l}\mathrm{Xe}-133 \\
\mathrm{Kr}-85 \text { and } \\
\mathrm{R}_{\mathrm{n}}-222\end{array}$ & 2 & $\mathrm{~A} 3$ \\
\hline $\begin{array}{c}\left(10^{-8} \sim 10^{-4}\right) \\
\mathrm{e}^{-39,440 / R T} \\
\left\{1.1 \times 10^{-31} \sim-27\right\} \\
<7.8 \times 10^{-27} \sim-23>\end{array}$ & $\begin{array}{l}600- \\
1300\end{array}$ & $\mathrm{UO}_{2+\mathrm{x}(\mathrm{x}<1)}$ & $\mathrm{Xe}-133$ & 3 & A1 \\
\hline $\begin{array}{c}1.5 \times 10^{-10} \times \mathrm{e}^{-18,600 / R T} \\
\left\{2.2 \times 10^{-21}\right\} \\
<4.0 \times 10^{-19}>\end{array}$ & $\begin{array}{l}500- \\
1100\end{array}$ & $\mathrm{U}_{3} \mathrm{O}_{8}$ & $\mathrm{Xe}-133$ & & A4 \\
\hline
\end{tabular}

1 The first value was for $5 \times 10^{12}$ fission $/ \mathrm{cm}^{3}$; and the second was for $6 \times 10^{14}$ fission $/ \mathrm{cm}^{3}$. The extent of the fission did not change D significantly.

2 Burnup increased $D$ to a factor of the maximum of 1,000 .

3 No correlation between $D$ and $x$.

a I-131 and Xe-133 releases increased with $(\mathrm{O} / \mathrm{U})$ ratio, reached the maximum (a factor of approximately 17 , with varying temperature to $100 \mathrm{C}$ ) at $\mathrm{UO}_{2.20}$, and dropped to the minimum at $\mathrm{UO}_{2.25}$, but increased significantly at $\mathrm{UO}_{2.62}$ (Shiba, 1975).

b There were two contradictory observations that diffusivities of fission gases increased linearly with or were independent of, $(\mathrm{O} / \mathrm{U})$ ratio (Shiba, 1975).

c Diffusivities were calculated using Arrhenius equations given here from higher temperatures.

References: (A1) - Wohler, 1976, 1969; (A2) - Belle et al., 1960; (A3) - Belle, 1961; (A4) Lindner and Matzke, 1959. 
Among the various possibilities of fast solid-state diffusion, the author selects diffusion in the $\mathrm{U}_{3} \mathrm{O}_{8}$ matrix as an example. Xe-133 diffusivity has been measured in the higher oxide (Lindner and Matzke, 1959). Xe-133 diffusivity is presumably slower than or closer to the diffusivities of $\mathrm{Cl}-36, \mathrm{Tc}-99, \mathrm{I}-129$, and Cs-135, because the atomic number of Xe-133 is bigger than or closer to the rest. Therefore, Xe-133 diffusivity can be used as a conservative approximation -- $D_{m}$ for Xe-133 $\simeq 1.5 \times 10^{-10}\left(\mathrm{~cm}^{2} / \mathrm{sec}\right.$.) $\mathrm{e}^{-18.6 \mathrm{kcal} /(\mathrm{mol}-\mathrm{K}) / \mathrm{RT}}$ (from data by Lindner and Matzke, 1959). With this diffusivity at 200 and $100 \mathrm{C}$, all Xe-133 will be released from fractured $\mathrm{U}_{3} \mathrm{O}_{8}$ particles $(\sim 1 \mu \mathrm{m})$ within 1,000 and 10,000 years, respectively. Recent measurements show that similar conclusion may be made even in lower oxides, if shortcircuit diffusion paths (such as dislocations) are abundant (Mansouri, 1995).

This approximation assumes that all these radionuclides exist as solid solutions. Some of Tc-99 is likely to be present as intermetallic compounds (Thomas and Guenther, 1989). The compounds will be essentially immobile. In addition, if the diffused radionuclides to the SF surface are not reactive with air or groundwater, the radionuclides may diffuse back into the matrix. Tc-99 is likely to oxidize with air (Gray and Wilson, 1995), but how other radionuclides react with air or moisture are not known. Therefore, this diffusion calculation provides a conservative estimate.

In summary, the oxidation of SF matrix is expected to increase releases of Pu-(239+240), Am- $(241+243), \mathrm{C}-14, \mathrm{Cl}-36$, Tc-99, I-129, and Cs-135 under saturated or unsaturated aqueous conditions, through (a) increase of matrix dissolution rates, (b) increase of solubility limits or colloid formation, or (c) increase of surface area. Unlike C-14, I-129 releases are likely to be small upon the lower oxidation in dry-air environments. However, the higher oxidation possibly releases $\mathrm{Cl}-36$, Tc-99, I-129, and Cs-135 fast in dry-air environments.

\section{PERFORMANCE OF CLADDING MATERIALS}

In this section, oxidation behavior of cladding under anticipated repository conditions will be evaluated. Cox (1976) has reviewed oxidation characteristics of Zircaloy extensively. Rothman (1984) has evaluated these Zircaloy characteristics further in tuff environments. More recently, Einziger (1994) has focused on the dry oxidation of Zircaloy. All these analyses are based on the following physical phenomena. Compact and protective oxides form initially. This initial oxide is called pretransition oxide. After a finite thickness of the pretransition oxide forms, the porous nonprotective oxide forms subsequently. Growth of the pretransition oxide follows a time law of one-third power; growth of the post-transition oxide follows a linear time law. Another explanation from Bryner (1979) is that a new pretransition oxide grows, once the preceding pretransition oxide reaches a finite thickness. At this point of a new layer formation, the preceding pretransition oxide fractures. On the basis of Bryner's postulate, Clayton and Fischer (1985) interpreted the linear time law as the averaged kinetics of repeated formations of the pretransition oxide layer. 
From these data, three different cases of oxidation kinetics can be postulated under repository conditions. The first is the formation of pretransition oxide, followed by the growth of posttransition oxide. The second is the growth of post-transition oxide only, on preexisting oxides from reactor operations. The third is the repeated growth of pretransition oxide. Table 7 shows calculated oxide thickness and transition time for these three cases, using formula obtained at temperatures of from 232 to approximately $400 \mathrm{C}$. The cladding of approximately $0.06 \mathrm{~cm}$ may not oxidize completely after 10,000 years, at 100 to $150 \mathrm{C}$, unless other fastdiffusion mechanisms operate. At $200 \mathrm{C}$, oxidation may be complete only with the aid of neutron irradiation (Clayton and Fischer, 1985). However, unlike the reactor environment, neutron irradiation will not be significant under repository conditions.

Table 7 Calculated Cladding Thickness Oxidized and Transition Time From Protective Pretransition Oxide to Non-Protective Post-transition Oxide ${ }^{a}$

\begin{tabular}{||c|c|c|c|c||}
\hline \multirow{2}{*}{$\begin{array}{c}\text { Temperature } \\
\text { (C) }\end{array}$} & \multirow{2}{*}{$\begin{array}{c}\text { Transition } \\
\text { Time } \\
\text { (Years) }\end{array}$} & \multicolumn{3}{|c|}{\begin{tabular}{c} 
Thickness Oxidized (cm for 10,000 Years) \\
\cline { 3 - 5 }
\end{tabular}} \\
\cline { 3 - 5 } & $\begin{array}{c}\text { Pretransition } \\
\text { and } \\
\text { Post-transition }\end{array}$ & $\begin{array}{c}\text { Post- } \\
\text { transition } \\
\text { Only }\end{array}$ & $\begin{array}{c}\text { Cyclic } \\
\text { Pretransition }\end{array}$ \\
\hline 100 & $1.6 \times 10^{5}$ & $2.9 \times 10^{-5}$ & $4.6 \times 10^{-6}$ & $2.9 \times 10^{-5}$ \\
\hline 150 & 3600 & $2.4 \times 10^{-4}$ & $2.4 \times 10^{-4}$ & $2.4 \times 10^{-4}$ \\
\hline 200 & 180 & $5.6 \times 10^{-3}$ & $5.6 \times 10^{-3}$ & $5.6 \times 10^{-3}$ \\
\hline
\end{tabular}

a From the summaries made by Rothman (1984) and Clayton and Fischer (1985), the oxidation kinetics at 232 to approximately $400 \mathrm{C}$ are:

Pretransition $\Delta \mathrm{W}^{3}=6.36 \times 10^{11} \mathrm{e}^{-13,636 / \mathrm{T}} \mathrm{t}$, post-transition $\Delta \mathrm{W}=75.3 \mathrm{x} \mathrm{e}^{-556 / \mathrm{T}}+1.12 \times 10^{8}$

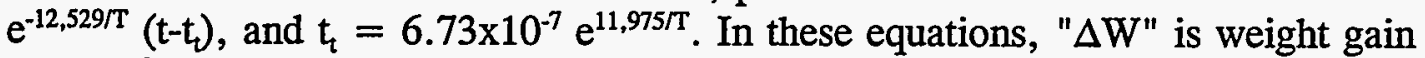
$\left(\mathrm{mg} / \mathrm{dm}^{2}\right), " \mathrm{t}$ " is time (day), and " $\mathrm{t}_{\mathrm{e}}$ " is time to transition (days). Zircaloy density is 6.56 (ASM International, 1990) and effects of neutron irradiation are assumed insignificant. More recent summaries made by Einziger (1994) were not used because applicable temperatures were higher.

Pretransition oxidation kinetics were considered essentially the same in water, steam, or air, at $350 \mathrm{C}$ (Einziger, 1994; Fraker, 1993). If oxidation mechanisms do not change at lower repository temperatures, the present evaluation will be valid in all three repository environments.

All these calculations are based on data obtained from about 300 to $400 \mathrm{C}$, except one from $232 \mathrm{C}$ (Rothman, 1984). Therefore, under repository conditions of lower temperatures for longer periods, individual grains may oxidize, instead of uniform surface oxidation. Grain boundaries are considered to oxidize rapidly, before the onset of matrix oxidation of individual grains. The preferential oxidation of grain boundaries has been reported in 
Zircaloy oxidation (Cox, 1976). The numerical evaluation of Equation 8 using the oxygen diffusivity in alpha-Zircaloy (Wohler, 1976,1969) will result in much less oxidation than that in Table 7. However, if results in Table 7 represent the oxidation kinetics of individual grains (of about $10 \mu \mathrm{m}$ (Fraker, 1993), significant oxidation may occur at temperatures above $150 \mathrm{C}$. If oxygen diffusion along grain boundaries is restricted, oxidation will become slower. Therefore, microstructural variation (such as cracks or pores) during oxidation seems to play an important role for providing fast diffusion paths of oxygen for the subsequent oxidation of individual grains.

Following the postulate made regarding the oxidation of SF matrix, a threshold temperature possibly exists also for the formation of post-transition oxide. In fact, Kass (1969) obtained only pretransition oxides at 232 to $316 \mathrm{C}$ in deionized water. Therefore, the threshold temperature is likely to be above $200 \mathrm{C}$, if existent. The formulation (Equations 3 and 4) used for the threshold temperature for the SF matrix oxidation may apply to the formation of post-transition oxide.

Regarding fracture of cladding materials, it is expected that volume contracts approximately 10 percent, associated with oxidation. The plastic deformation of unoxidized Zircaloy will accommodate a significant portion of the elastic energy associated with the contraction. This postulate is consistent with the observation that no extensive cracks have been reported in pretransition oxidation. The only cracks observed were at the interface of $\mathrm{ZrO}_{2}$ and defects such as voids or impurities (Cox, 1960). However, the porous structure of the post-transition oxide showed fractures associated presumably with cumulative stress (Rothman, 1984).

The radionuclide of concern in the cladding failure is primarily $\mathrm{C}-14$, as an activated radionuclide (Smith and Baldwin, 1993, 1989; Park and Pflum, 1990; Van Konynenburg et al., 1987, 1985). As in the SF matrix, details on C-14 releases from Zircaloy were described in another paper by Ahn (1994). Summarizing Ahn's paper, significant C-14 releases in terms of its inventory from unoxidized or oxidized Zircaloy cladding are unlikely under anticipated conditions. This is because (a) C-14 diffusivity in unoxidized Zircaloy is small (unless effects of radiation, impurities, defects, or grain boundaries are significant) and (b) Zircaloy oxidation is slow, although C-14 releases are fast in oxidized Zircaloy.

\section{CONCLUSIONS}

This report has evaluated the oxidation behavior and fracture in LWR SF in dry air. Subsequently, it has discussed their effects on radionuclide releases in the anticipated repository environments. This study has led to the following conclusions:

(1) Within the premise of traditional diffusion-limited kinetics, the oxidation kinetics of moderate or high burnup SF may follow a sphere model. The sphere model describes the kinetics well because the grain boundary oxidation is so fast that it can be neglected in overall kinetics of oxygen diffusion. Numerical evaluation of this sphere model shows uncertainties about whether the oxidation to lower oxides will be complete within 10,000 years, under anticipated repository conditions. 
(2) Reaction-limited kinetics as alternate kinetics may lead to a threshold temperature below which higher oxides, such as $\mathrm{U}_{3} \mathrm{O}_{8}$, may not form. Fission product chemistry and radiation effects are likely to destabilize $\mathrm{U}_{3} \mathrm{O}_{8}$ below the threshold temperature. The nucleation process, as one of the reaction-limited kinetics, is proposed to formulate the time delay for the $\mathrm{U}_{3} \mathrm{O}_{8}$ formation mathematically. Uncertainties associated with the nucleation and the threshold temperature remain regarding (a) the likelihood of the presence of amorphous $\mathrm{U}_{3} \mathrm{O}_{8}$ below the threshold temperature, (b) temperature sensitivity of the time delay, (c) details for nucleation and growth, and (d) effects of fission product chemistry and radiation. If higher oxides form, their growth kinetics are likely to be slow compared with those of lower oxides at anticipated repository temperatures.

(3) Fracture properties that result from oxidation have been evaluated in order to learn the extent of stress generated and the subsequent increase of fracture-induced surface area. A simple elastic model shows high stresses to induce fracture and large surface area, upon higher oxide formation. Uncertainties associated with this calculation remain regarding (a) the use of elastic energy to create new surface areas by fracture and (b) strain localization at grain boundaries.

(4) Upon SF matrix oxidation, releases of Pu-(239+240), Am-(241+243), C-14, Cl-36, Tc99, I-129, and Cs-135 are expected to increase under saturated or unsaturated aqueous conditions, through (a) the increase of matrix dissolution rates, (b) increase of solubility limits or colloid formation, and (c) increase of surface area. Unlike C-14, I-129 releases are likely to be small upon the lower oxidation under anticipated conditions. However, the higher oxidation possibly releases $\mathrm{Cl}-36$, Tc-99, I-129, and Cs-135 quickly.

(5) Under anticipated conditions, Zircaloy oxidation appears insignificant, unless each grain oxidizes. Fracture and C-14 releases upon Zircaloy oxidation have been discussed.

The last important step in this report is to summarize how the assessments made here are used for licensing applications. This report has evaluated various factors involved in radionuclide releases and assessed the amounts of radionuclide releases: many assumptions involved in data interpretation or modeling; numerical numbers of radionuclide releases; mathematical formulas; and physical processes. In TSPA, the obtained quantitative values of radionuclide releases will be used in calculations of source terms. For instance, Equations 1, $2,3,4,5$, and 6 , and Table 7 will be directly used. All assumptions and potential physical processes will be used in determining various cases (scenarios) in the calculations. The following various kinetics are provided: diffusion limit in Section 2.1.; reaction limit and retardation of higher oxide formation in Section 2.2; and fracture in Section 3. Additionally, the overall knowledge obtained will be the basis for prelicensing reviews: Sections 2 and 3 are on oxidation of SF matrices; Section 4 discusses the radionuclide releases as consequences of oxidation; and Section 5 discusses cladding behavior. 


\section{REFERENCES}

Ahn, T. M., "Long-term Kinetic Effects and Colloid Formation in Dissolution of LWR Spent Fuels", NUDOC Accession Number: 9508030112, U.S. Nuclear Regulatory Commission, Washington, DC, 1995.

Ahn, T. M., "Long-term C-14 Source Term for a High-level Waste Repository," Waste Management, 14: 393, 1994.

ASM International, Metals Handbook, American Society for Metals, Metals Park, OH, 1990.

Ball, R. G. J., and R. W. Grimes, "A Comparison of the Behavior of Fission Gases in $\mathrm{UO}_{2 \pm \mathrm{x}}$ and $\alpha-\mathrm{U}_{3} \mathrm{O}_{8 \cdot \mathrm{z}}, " J$. Nucl. Mat., 188: 216, 1992.

Belle, J., Uranium Dioxide: Properties and Nuclear Applications, U.S. Atomic Energy Commission, Washington, DC, 1961.

Belle, J., A. B. Auskern, W. A. Bostrom, F. S. Susko, "Diffusion Kinetics in Uranium Dioxide," Proceedings of the Fourth International Symposium on the Reactivity of Solids, Amsterdam, The Netherlands, 1: 452, 1960.

Boase, D. G., and T. T. Vandergraaf, "The Canadian Spent Fuel Storage Canister: Some Materials Aspects," Nucl. Tech., 32: 60, 1977.

Bryner, J. S., "The Cyclic Nature of Corrosion of Zircaloy-4 in $633 \mathrm{~K}$ Water," J. Nucl. Mat., 82: 84, 1979.

Cahn, J. W., and R. J. Charles, "The Initial Stages of Phase Separation in Glasses," Phys. and Chem. Glasses, 6: 181, 1965.

Campbell, T. K., E. R. Gilbert, C. K. Thornhill, and B. J. Wrona, "Oxidation Behavior of Spent $\mathrm{UO}_{2}$ Fuel, "Nuclear Tech., 84: 182, 1989a.

Campbell, T. K., E. R. Gilbert, G. D. White, G. F. Piepel, and B. I. Wrona, "Oxidation Behavior of Nonirradiated $\mathrm{UO}_{2}$," Nucl. Tech., 85: 160, $1989 \mathrm{~b}$.

Christian, V. The Theory of Transformations in Metals and Alloys, Pergamon Press, New York, NY, 1965.

Clayton J. C., and R. L. Fischer, "Corrosion and Hydriding of Zircaloy Fuel Rod Cladding in $633 \mathrm{~K}$ Water and Reactor Environments, " DOE/NE/34130-1-Vol. 1 (CONF-850401Vol. 1), Proceedings of the American Nuclear Society Topical Meeting on Light Water Reactor Fuel Performance, Orlando, FL, April 1985. 
Codell, R., "Model for Release of Gaseous ${ }^{14} \mathrm{C}$ from Spent Fuel," Proceedings of the Third International Conference on High-Level Radioactive Waste Management, Las Vegas, NV, 1: 22, 1993.

Cox, B., "Oxidation of Zirconium and Its Alloys," Advances in Corrosion Science and Technology, Vol.5, (M. R. Fontana and R. W. Staehle, Eds.), Plenum Press, New York, NY, 1976.

Cox, B., "The Oxidation and Corrosion of Zirconium and its Alloys," Corr. 16: 124, 1960.

Crank, J. The Mathematics of Diffusion, Second Edition, Clarendon Press, Oxford, UK, 1975.

Einziger, R. E., "Preliminary Spent LWR Fuel Oxidation Source Term Model," Proceedings of the Fifth International Conference on High-Level Radioactive Waste Management, 2: 554, 1994.

Einziger, R. E., "Oxidation Testing of Spent Fuel," Presented to Nuclear Waste Technical Review Board - Full Board Meeting, Pacific Northwest Laboratory, Las Vegas, NV, 1992.

Einziger, R. E., L. E. Thomas, H. C. Buchanan, and R. B. Stout, "Oxidation of Spent Fuel in Air at 175 to $195 \mathrm{C}, \mathrm{J}$. Nucl. Mat., 190: 53, 1992.

Einziger, R. E., S. C. Marschman, and H. C. Buchanan, "Spent-fuel Dry-bath Oxidation Testing," Nucl. Tech., 94: 383, 1991.

Einziger, R., and H. C. Buchanan, "Long-term, Low-temperature Oxidation of PWR Spent Fuel," WHC-EP-0070, Westinghouse Hanford Company, Richland, WA, 1988.

Einziger, R. E., and R. V. Strain, "Behavior of Breached Pressurized Water Reactor Spentfuel Rods in an Air Atmosphere between 250 and 360 C," Nucl. Tech., 75: 82, 1986.

Einziger, R. E., and R. E. Woodley, "Evaluation of the Potential for Spent Fuel Oxidation under Tuff Repository Conditions," HEDL-7452, Hanford Engineering Development Laboratory, Richland, WA, 1985.

Finch, R. J., and R. C. Ewing, "Uraninite Alteration in an Oxidizing Environment and Its Advance to the Disposal of Spent Nuclear Fuel," SKB TR-91-15, Swedish Nuclear Fuel and Waste Management Co., Stockholm, Sweden, 1990.

Finn, P. A., J. K. Bates, J. C. Hoh, J. W. Emery, L. D. Hafenrichter, E. C. Buck, and M. Gong, "Elements Present in Leach Solutions From Unsaturated Spent Fuel Tests," (A. Barkatt and R. A. Van Konynenburg, Eds.), Mat. Res. Soc. Symp. Proc., 333: 399, 1994. 
Fraker, A. C., "Corrosion of Zirconium and Zirconium Alloys," Evaluation and Compilation of DOE Waste Package Test Data, Biannual Report, August 1989 - January 1990, (C. Interrante, A. Fraker and E. Escalante, Eds.), NUREG/CR-4735, Vol.8, National Institute of Standards and Technology, Gaithersburg, MD, 1993.

Grambow, B., "Spent Fuel Dissolution and Oxidation: An Evaluation of Literature Data," SKB TR-89-13, Swedish Nuclear Fuel and Waste Management Co., Stockholm, Sweden, 1989.

Gray, W. J., L. E. Thomas, and R. E. Einziger, "Effects of Air Oxidation on the Dissolution Rate of LWR Spent Fuel," Mat. Res. Soc. Symp. Proc., 294:47, 1993.

Gray, W. J., and C. N. Wilson, "Spent Fuel Dissolution Studies FY 1991 to 1994," PNL10540, Pacific Northwest National Laboratory, Richland, WA, 1995.

Harrison, K. T., C. Padgett, and K. T. Scott, "The Kinetics of the Oxidation of Irradiated Uranium Dioxide Spheres in Dry Air," J. Nucl. Mat., 23: 121, 1967.

Kass, S., "Aqueous Corrosion of the Zircaloys at Low Temperatures," J. Nucl. Mat., 28: 315, 1969.

Kingery, W. D., H. K. Bowen, and D. R. Uhlmann, Introduction to Ceramics, John Wiley and Sons, New York, NY, 1976.

Kofstad, P., Nonstoichiometry, Diffusion and Electrical Conductivity in Binary Metal Oxides, Wiley-Interscience, New York, 1972.

Lawrence Livermore National Laboratory, "Yucca Mountain Site Characterization Project (YMP) Status Report," April 1995 Status Report, Livermore, CA, 1995.

Lin, M., G. B. Olson, and M. Cohen, "Distributed-activation Kinetics of Heterogeneous Martensitic Nucleation," Met. Trans., 23A: 2987, 1992.

Lindner, Von R., and Hj. Matzke, "Diffusion von Xe-133 in Uranoxyd Verschiedenen Sauerstoffgehaltes," Zeitschrift für Naturforschung, 14a: 582, 1959.

Mansouri, M. A., "Release of Fission Products From Lightly-Irradiated $\mathrm{UO}_{2+\mathrm{x}}$, Ph.D Thesis, University of California, Berkeley, CA, 1995.

Martin, D. M., "Fracture in Glass and High-Level Canisters," NUREG/CR-4198, Iowa State University, Ames, IA, 1985.

Matzke, Hj., "Radiation Damage in Crystalline Insulators, Oxides and Ceramic Nuclear Fuels," Rad. Eff., 64: 3, 1982. 
Matzke, $\mathrm{Hj}$., "Ion-bombardment-induced Structural Changes in $\mathrm{Fe}_{2} \mathrm{O}_{3}, \mathrm{Cr}_{2} \mathrm{O}_{3}$ and $\mathrm{U}_{3} \mathrm{O}_{8}$," Rad. Eff., 28: 249, 1976.

McClintock, F. A., and A. S. Argon, Mechanical Behavior of Materials, Addison Wesley Co., Reading, MA, 1966.

Naguib, M., and R. Kelly, "Criteria for Bombardment-induced Structural Changes in Onmetallic Solids," Rad. Eff., 25: 1, 1975.

Olander, D. R., "Combined Grain Boundary and Lattice Diffusion in Fine-Grained Ceramics," Advances in Ceramics, 17, Proceedings of the Symposium on Fission-Product Behavior in Ceramic Oxide Fuel, American Ceramic Society, Columbus, OH, 1986.

Park, U. S., and C. G. Pflum, "Requirements for Controlling a Repository's Releases of Carbon-14 Dioxide: The High Costs and Negligible Benefits," Proceedings of the Fifth International Conference on High-Level Radioactive Waste Management Conference, 2: 1158, 1990.

Posey-Dowty, J., E. Axtman, D. Crerar, M. Borscik, A. Ronk, and W. Wood, "Dissolution Rate of Uraninite and Uranium Roll-front Ores," Econ. Geol., 82: 184, 1987.

Rothman, A. J., "Potential Corrosion and Degradation Mechanisms of Zircaloy Cladding on Spent Nuclear Fuel in a Tuff Repository," UCID-20172, Lawrence Livermore National Laboratory, Livermore, CA, 1984.

Russel, K. C., "Linked Flux Analysis of Nucleation in Condensed Phases," Acta Met., 16: $761,1968$.

Sauthoff, G., "Orienting of Precipitating Au Particles in a Fe-Mo-Au Alloy by External Elastic Stress," Z. Metallkde, 67: 25, 1976.

Schackelford, J. F., The CRC Materials Science and Engineering Handbook, CRC Press, Cleveland, OH, 1992.

Schmets, J., "Pretreatment of Irradiated Fuels, Quarterly Report 14, July 1-September 30, 1963," EURAEC-884, US-EURATOM Joint Research and Development Program, MOL, Belgium, 1963.

Shewmon, P. G., Transformations in Metals, McGraw-Hill, New York, NY, 1969.

Shiba, K., "Fission Iodine and Xenon Release From the $\mathrm{UO}_{2}-\mathrm{U}_{3} \mathrm{O}_{8}$ System With Emphasis on Radiation Damage," J. Nucl. Mat., 57: 271, 1975.

Shoesmith, D. W., and S. Sunder, "An Electrochemistry-Based Model for the Dissolution of $\mathrm{UO}_{2}$," AECL-10488, Atomic Energy of Canada Limited, Pinawa, Canada, 1991. 
Smith, H. D., and D. L. Baldwin, "An Investigation of Thermal Release of Carbon-14 From PWR Zircaloy Spent Fuel Cladding" The American Nuclear Society Topical Meeting on Nuclear Waste Isolation in the Unsaturated Zone (FOCUS'89), Las Vegas, NV, September, 1989, or J. Nucl. Mat., 200: 128 (1993).

Stacy, R. G., and J. H. Goode, "Voloxidation and Dissolution of Irradiated LWR Fuel," Am. Nucl. Soc., 19: X.11, 1978.

Steward, S. A., "Dissolution Modeling and $\mathrm{UO}_{\mathrm{x}}$ Flow-through Testing," Presentation in DOE/NRC Technical Exchange on EBS Release Rates and Waste Form Testing, Las Vegas, NV, 1995.

Stout, R. B., E. J. Kansa, and A. M. Wijesinghe, "Kinematics and Thermodynamics Across a Propagating Non-stoichiometric Oxidation Phase Front in Spent Fuel Grains," UCRL-JC112821, Lawrence Livermore National Laboratory, Livermore, CA, 1993a.

Stout, R. B., E. J. Kansa, and A. M. Wijesinghe, "Kinematics and Thermodynamics of Non-stoichiometric Oxidation Phase Transitions in Spent Fuel," Mat. Res. Soc. Symp. Proc., 294: $25,1993 b$.

Stout, R. B., and H. Leider, "Preliminary Waste Form Characteristics Report", Version 1.0, UCRL-ID-108314 Rev.1, Lawrence Livermore National Laboratory, Livermore, CA, 1994.

Stout, R. B., H. F. Shaw, and R. E. Einziger, "Statistical Model for Grain Boundary and Grain Volume Oxidation Kinetics in UO Spent Fuel," Mat. Res. Soc. Symp. Proc., 176: 475, 1990.

Swalin, R. A., Thermodynamics of Solids, Second Edition, John Wiley \& Sons, New York, NY, 1972.

Taylor, P., R. J. Lemire, and D. D. Wood, "The Influence of Moisture on Air Oxidation of $\mathrm{UO}_{2}$ : Calculations and Observations," Proceedings of the Third International Conference on High-Level Radioactive Waste Management, 2: 1442, 1992a.

Taylor, P, D. D. Wood, and A. M. Duclos, "The Early Stage of $\mathrm{U}_{3} \mathrm{O}_{8}$ Formation on Unirradiated CANDU UO ${ }_{2}$ Fuel Oxidized in Air at 200-300 C," J. Nucl. Mat., 189: 116, 1992b.

Taylor, P., D. D. Wood, D. G. Owen, W. G. Hutchings, and A. M. Duclos, "Microstructures and Phase Relationships of Crystalline Oxidation Products Formed on Unused CANDU Fuel Exposed to Aerated Steam and Aerated Water near 200 C," AECL Research Report, AECL-10476, Pinawa, Canada, 1991.

Taylor, P., E. A. Burgess, and D. G. Owen, "An X-ray Diffraction Study of the Formation of $\beta-\mathrm{UO}_{2.33}$ on the $\mathrm{UO}_{2}$ Pellet Surfaces in Air at 229 to 275C", J. Nucl. Mat., 88: 153, 1980. 
Tempest, P. A., P. M. Tucker, and J. W. Tyler, "Oxidation of $\mathrm{UO}_{2}$ Fuel Pellets in Air at 503 and $543 \mathrm{~K}$ Studied Using X-ray Photoelectron Spectroscopy and X-ray Diffraction," J. Nucl. Mat., 151: 251, 1988.

Thomas, L. E., R. E. Einziger, and H. C. Buchanan, "Effect of Fission Products on Airoxidation of LWR Spent Fuel," J. Nucl. Mat., 210: 310, 1993.

Thomas, L. E., and R. E. Einziger, "Grain Boundary Oxidation of Pressurized-Water Reactor Spent Fuel in Air," Mat. Charac., 28: 149, 1992.

Thomas, L. E., R. W. Knoll, L. A. Charlot, J. E. Coleman, and E. R. Gilbert, "Storage of LWR Spent-Fuel in Air," Vol. 2, PNL-6640, Pacific Northwest Laboratory, Richland, WA, 1989a.

Thomas, L. E., R. E. Einziger, and R. E. Woodley, "Microstructural Examination of Oxidized Spent PWR Fuel by Transmission Electron Microscopy," J. Nuc. Mat., 166:243, 1989b.

Thomas, L. E., and R. J. Guenther, "Characterization of Low-Gas-Release LWR Fuels by Transmission Electron Microscopy," Mat. Res. Soc. Symp. Proc., 127: 293, 1989.

Van Konynenburg, R. A., "Behavior of Carbon-14 in Waste Packages for Spent Fuel in a Tuff Repository," Waste Management, 14: 363, 1994.

Van Konynenburg, R. A., C. F. Smith, H. W. Culham, and H. D. Smith, "Carbon-14 in Waste Packages for Spent Fuel in a Tuff Repository," Mat. Res. Soc. Symp. Proc., 84: 185, 1987.

Van Konynenburg, R. A., C. F. Smith, H. W. Culham, and C. H. Otto, Jr., "Behavior of Carbon-14 in Waste Packages for Spent Fuel in a Repository in Tuff," Mat. Res. Soc. Symp. Proc., 44: 405, 1985.

Wilson, C. N., "Results From NNWSI Series 3 Spent Fuel Dissolution Tests," PNL-7170, Pacific Northwest Laboratory, Richland, WA, 1990.

Wohler, F. M., Diffusion and Defect Data, Vol.12 (1976) and Vol. 3 (1969), Trans. Tech. Publication, Bay Village, $\mathrm{OH}$.

Woodley, R. E., R. E. Einziger, and H. C. Buchanan, "Measurement of the Oxidation of Spent Fuel Between 140 and 225 C, Nucl. Tech., 85: 74, 1989.

Wronkiewicz, D. J., J. K. Bates, T. J. Gerding, and E. Veleckis, "Uranium Release and Secondary Phase Formation During Unsaturated Testing of $\mathrm{UO}_{2}$ at 90 C," J. Nuc. Mat., 190: 107, 1992. 


\section{TITLE AND SUBTITLE}

Dry Oxidation and Fracture of LWR Spent Fuel

\section{NUREG-1565}

DATE REPORT PUBLISHED

MONTH

November

YEAR

4. FIN OR GRANT NUMBER

5. AUTHOR(S)

6. TYPE OF REPORT

Tae M. Ahn

Technical

7. PERIOD COVERED (Inclusive Dates)

8, PERFORMING ORGANIZATION - NAME AND ADDRESS (If NRC, provide Division, Office or Region, U.S. Nuclear Regulatory Commission, and mailing address; if contractor, provide name and mailing address.)

\section{Division of Waste Management}

Office of Nuclear Material Safety and Safeguards

U. S. Nuclear Regulatory Commission

Washington, DC 20555-0001

9. SPONSORING ORGANIZATION - NAME AND ADDRESS (If NRC, type "Same as above"; if contractor, provide NRC Division, Office or Region, U.S. Nuclear Regulatory Commission, and mailing address.)

Same as above

\section{0, SUPPLEMENTARY NOTES}

\section{ABSTRACT (200 words orless)}

This report evaluates the characteristics of oxidation and fracture of light-water reactor (LWR) spent fuel in dry air. It also discusses their effects on radionuclide releases in the anticipated high-level waste repository environment. A sphere model may describe diffusion-limited formation of lower oxides, such as $\mathrm{U}_{4} \mathrm{O}_{9}$, in the oxidation of the SF matrix. Detrimental higher oxides, such as $\mathrm{U}_{3} \mathrm{O}_{8}$, may not form at temperatures below a thresnola temperature. The nucleation process suggests that a threshold temperature exists. The calculated results regarding fracture properties of the SF matrix agree with experimental observations. Oxidation and fracture of Zircaloy may not be significant under anticjpated conditions. Under saturated or unsaturated aqueous conditions, oxidation of the SF matrix is believed to increase the releases of Pu-(239+240),

Am-(241+243), C-14, Tc-99, I-129, and Cs-135. Under dry conditions, $1-129$ releases are likely to be small, unlike C-14, in lower oxides; $\mathrm{Cl}-36, \mathrm{TC}-99, \mathrm{I}-129$, and $\mathrm{Cs}-135$ may be released fast in higher oxides.

High-Level Waste, Spent Fuel, Dry Oxidation, Fracture, Cladding, Yucca Mountain, Radionuclide, Model, Review 


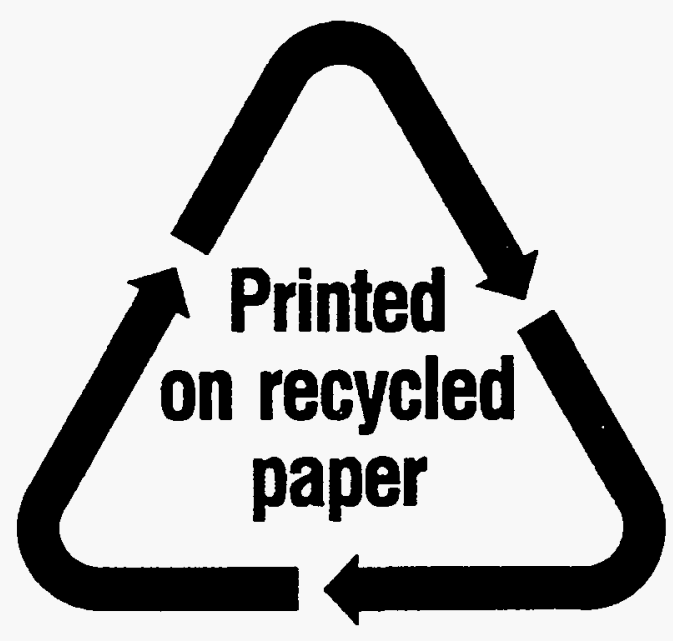

Federal Recycling Program 